\title{
Scientific Mapping of Papers Related to Health Literacy Using Co-Word Analysis in Medline.
}

\begin{abstract}
Background and Objective: It is necessary to study the emerging trends and areas of knowledge and to predict the direction of future research on the concept of health literacy in order to promote community health. Therefore, this study was conducted with the aim of mapping research knowledge in the field of health literacy and showing the structure of knowledge and their evolution over time. Materials and Methods: This scientometrics research was conducted using Co-word analysis technique includes the steps include: Data retrieval, Data analysis and Mapping and Visualization Papers from the MEDLINE database during (1970-2018) retrieved and analyzed. The bibliographic data analyzed using the visualization of similarities technique by text-mining and visualization techniques of VOSviewer. Results:A total of 7,429 documents, growth of scientific publications related to the field of health literacy has been increased rapidly over the past 10 years and continues to grow in recent years. The stronger studies were mainly conducted at research institutions of higher education in the Canada and United States. Four Core authors groups with a higher influence were identified. The keyword of "communication", "depression", "health education", and "internet" had respectively the highest frequency. The results of cluster analysis identified and categorized them into three major clusters. Health literacy field had a close relationship with the lifestyle dimensions, health information technology, mental health literacy and chronic diseases.

Conclusions: Given the interdisciplinary nature of health literacy the areas of education, health, Information Communication Technology (ICT) science, and mental health will help the cooperation of experts in these areas to enrich scientific research and make them more applicable.
\end{abstract}

Keywords: Co-word analysis, Health Literacy, MEDLINE, Science Mapping Paper Type: Research Article.

Citation (Vancouver): Karamali M, Yaghoubi M, Parandeh A. Scientific Mapping of Papers Related to Health Literacy Using Co-Word Analysis in Medline. Iran $J$ Health Educ Health Promot. Autumn 2021;9(3): 280-295.

Citation (APA): Karamali M., Yaghoubi M., Parandeh A. (Autumn 2021). Scientific Mapping of Papers Related to Health Literacy Using Co-Word Analysis in Medline. Iranian Journal of Health Education \& Health Promotion., 9(3), 280-295.
Mazyar Karamali

Health Management Research Center, Baqiyatallah University of Medical Sciences, Tehran, Iran.

MaryamYaghoubi

http://www.archtrauma.com/searchresult. asp?search=\&author=Mazyar+Karamali\& ournal=Y\&but_search=Search\&entries $=10$ $\& p g=1 \& s=0$ Health Management Research Center, Baqiyatallah University of Medical Sciences, Tehran, Iran

Akram Parandeh

* http://www.archtrauma.com/searchresult. asp?search=\&author=Amin+Sohrabi\&journ al=Y\&but_search=Search\&entries $=10 \& p g=1$ \&s=0Medicine, Quran and Hadith Research Center, Community Health Group,Nursing Faculty, Baqiyatallah University of Medical Sciences, Tehran, Iran.(Corresponding author) akram.parandeh@yahoo.com

Received: 2021/03/23

Accepted: 2021/07/26

Doi:10.52547/ijhehp.9.3.280 


\section{ترسيم نقشه علمى مقالات مرتبط باسواد سلامت با استفاده از تحليل}

هم رخدادى وازٔكانى در مدلاين

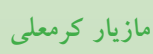
مركز تحقيقات مديريت سلامت، دانشكاه علوم بزشكى بقيه ا...(عج) مر تحقيمات مد

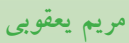
دانشيار، مركز تحقيقات مديريت سلامت، دانشكاء علوم يز شكى بقيه ا...(عج)

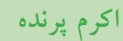
استاديار، مر كز تحقيقات طب، قرآن آن و حديث، ديار تمان

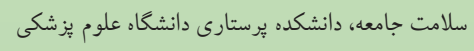

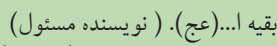
akram.parandeh@yahoo.com,

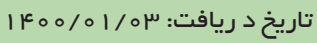

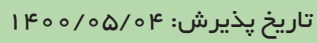

\section{:}

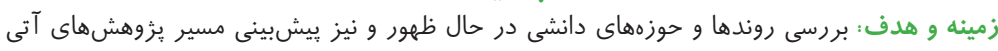

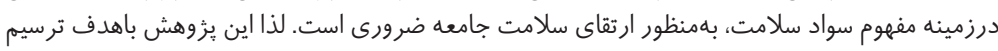

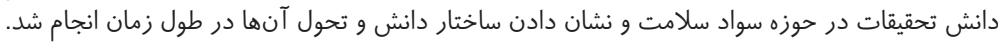

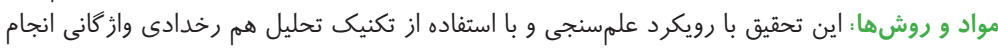

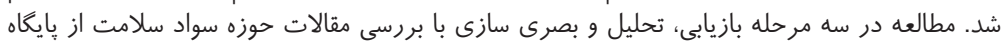

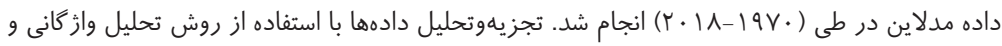

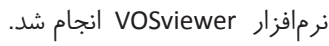

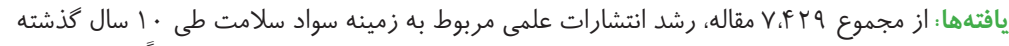

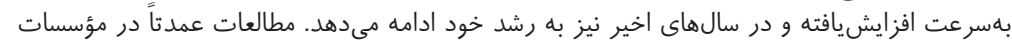

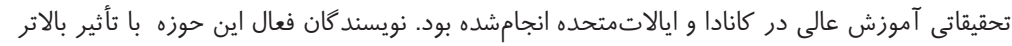

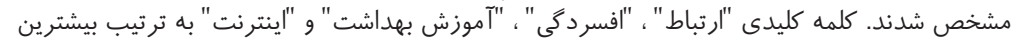

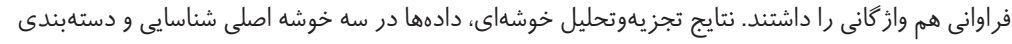

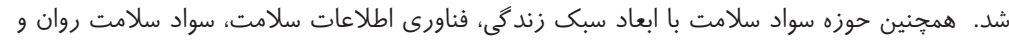

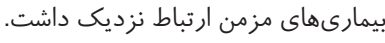

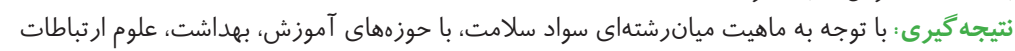

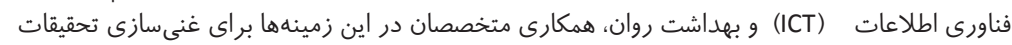

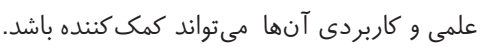

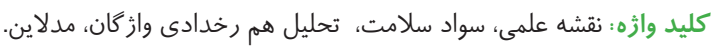
نوع مقاله : مطالعه يخوهشى.

4 استناد (ونكوور): كرمعلى م، يعقوبى م، مرنده ا. ترسيم نقشه علمى مقالات مرات مرتبط باسواد سلامت

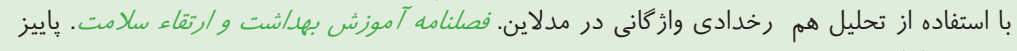

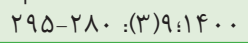

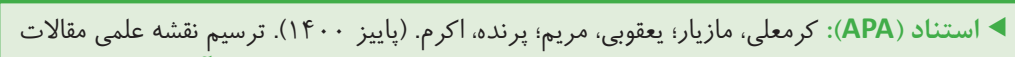

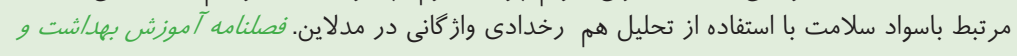


يرستارى و سلامت روان به سواد سلامت توجه شده است(ه (1). ازاينرو در بررسى اين حوزه دانشى و ارتباط آن با ساير

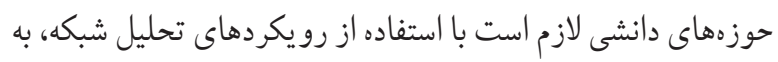

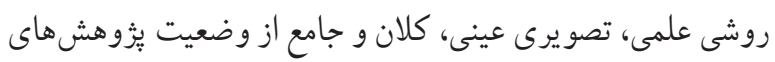

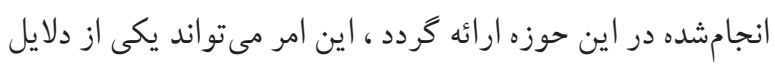
رواج تحليل شبكهاى هم نو يسندگى و هم واز گانى در مطالعات

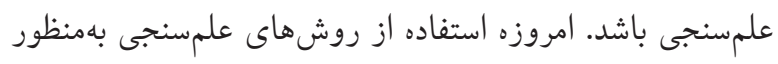

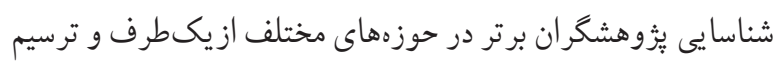

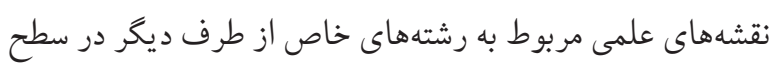
بين المللى رواج بسيارى يافته است(19 (1).

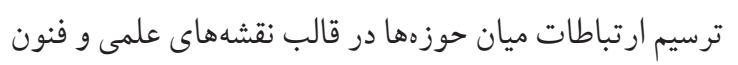

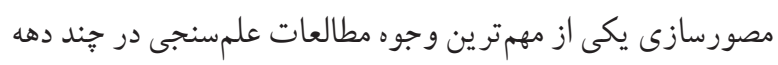

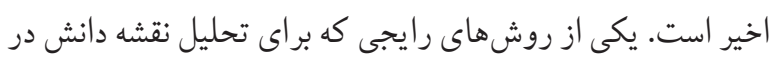

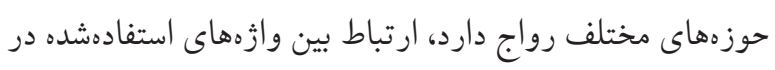

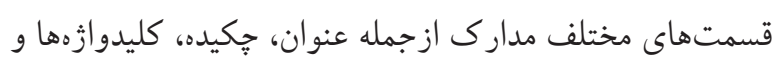

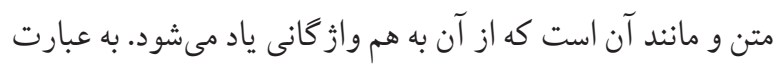
دقيقتر، تحليل هم واز كانى براى نكاشت رابطه ميان مفاهيم، انديشها

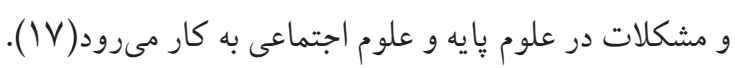

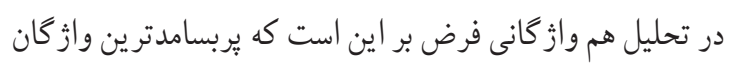
در مقايسه با وازگًان كمبسامد، تأثير بيشترى بر يك حوزه داشتهاند.

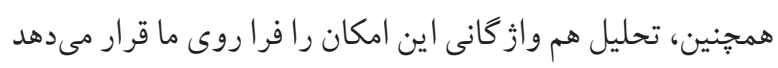

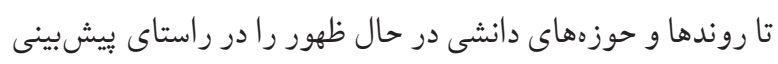

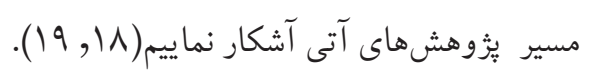

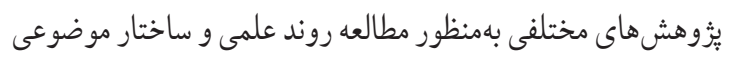

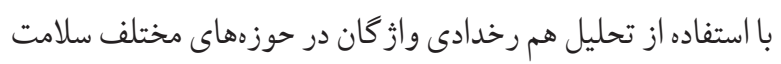

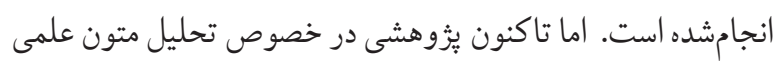

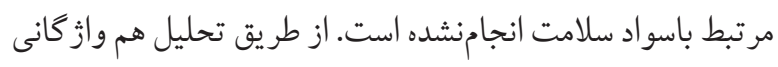

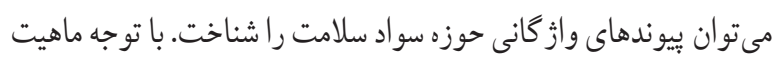

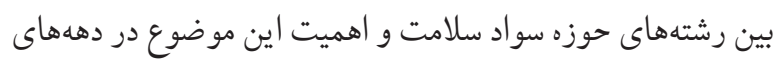

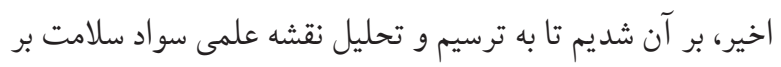

سواد سلامت بهعنوان يك مفهوم در ايالاتمتحده در ميانه دهه 197. به شيوههاى گوناكون تعريفشده است( (1). در يك تعريف جامع سواد سلامت بهعنوان ميزان ظرفيت افراد براى به دست آوردن، بردازش و درك اطلاعات و خدمات اساسى سلامت موردنياز براى تصميمات بيانشده داشته است(Y) وردات ورات درواقع سو اد سلامت گستره وسيعى از سطح فردى تا سطح جامعه

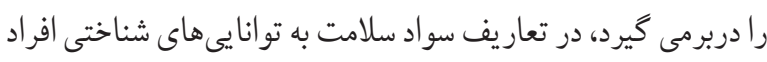

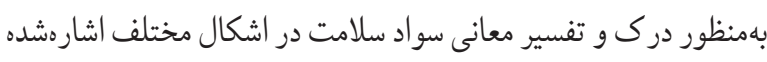
است. اين توانايى گاه به شكل تصميم گيرى و به كار گيرى اطلاعات كاه در بعد يردازش و تحليل اطلاعات و كاه به شكل به كار كيرى اطلاعات

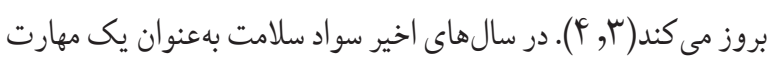

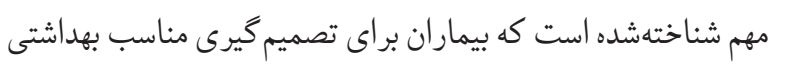

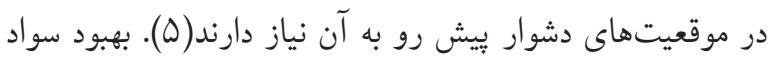
سلامت افراد منجر به بيامدهايى جون افزايش توانايى بالقوه بيماران جهت اخذ تصميمات آكاهانه، كاهش خطرات تهديد كننده سلامت،

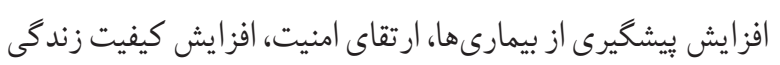

$$
\text { و افزايش كيفيت مراقبت از افراد مىشود(9-9 (9). }
$$

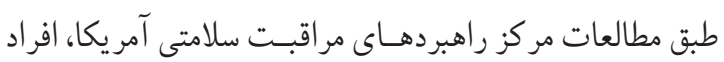

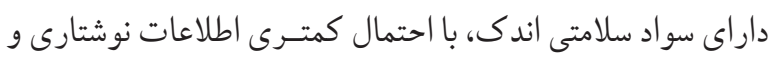

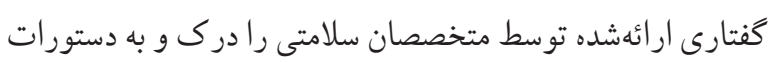

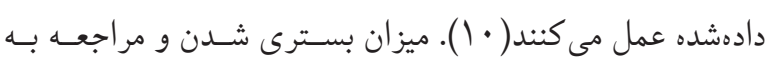

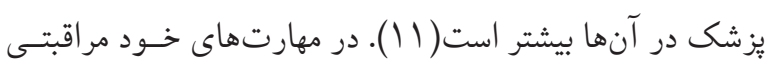
ضعيف عمل مى كنند( I ). مراقبت بيشكير انه كمترى دارند و درنتيجه

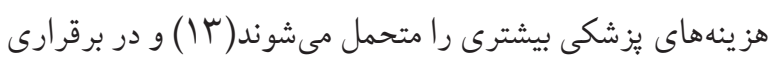

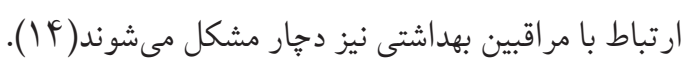
در اهميت مفهوم سواد سلامت مى توان كفت كه امروزه اين مفهوم

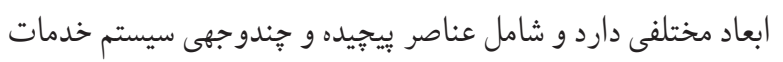

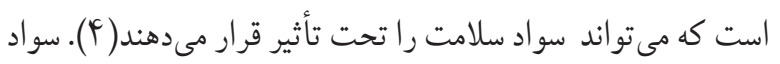

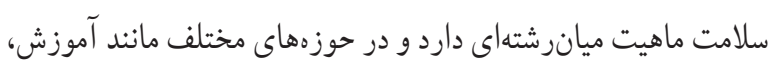


تشكيل ماتريس هم رخدادى، وزن دهى وازهها و تحليل وازهها و

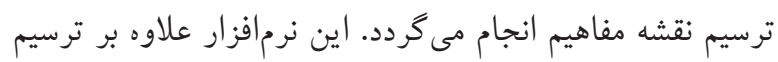

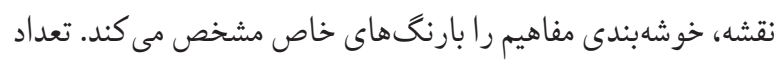
خوشهها با يك يار امتر ميزان وضوح resolution تعيين مىشود.

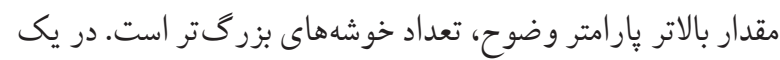
شبكه كتابسنجى، اغلب تفاوتهاى زيادى بين گرهها در تعداد

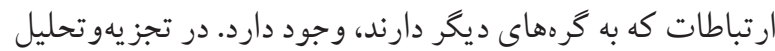

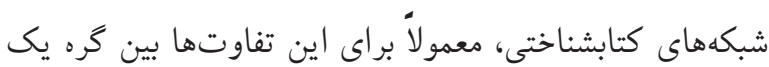

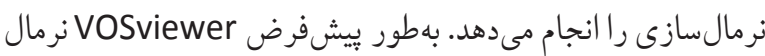
بودن شدت ارتباط را اعمال مى كند.

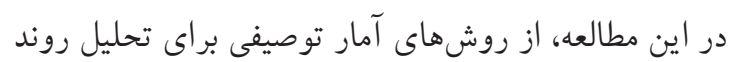
رشد مقالات در دورههاى زمانى، ميزان نرخ رشد مقالات درزمينه

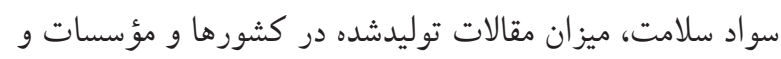
همجنين فراوانى حوزههاى دانشى مر تبط باسو اد سلامت استفاده شد.

\section{يافتهها}

تعداد VFT9 مدرك با ابزار جستجوى پيشرفته پاب مد درزمينه سواد

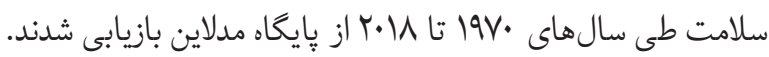
ظهور كليدواثههاى مرتبط باسواد سلامت از دهه •و آغازشده است.

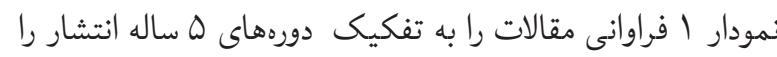

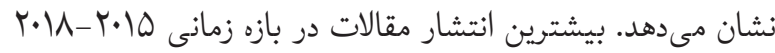

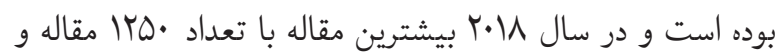
كمترين ميزان به تعداد ا مقاله مربوط به سال 1997 بوده است.

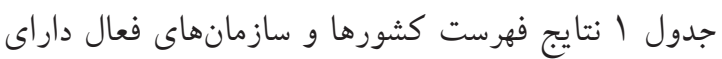
انتشار بيش از هـ مقاله درزمينه سواد سلامت را نشان مى دهد.

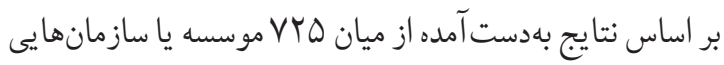

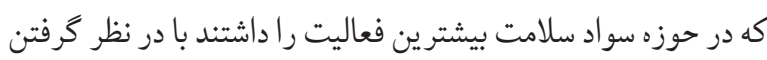

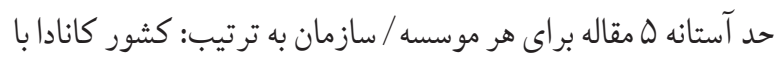

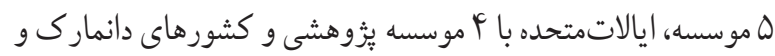
انغلستان بيشترين مقالات را تا سال 1 | • ب در مدلاين نمايه كردهاند. كشورهاى سوئيس، زاين، آلمان، ايرلند، و تايوان از ديخر كشورهاى
اساس دادههاى كتابشناختى پايخاه علمى و استنادى مدلاين بيردازيم.

$$
\text { روش كار }
$$

يُوهش حاضر از نوع مطالعات علمسنجى است كه با به كاركيرى فنون مصورسازى شبكههاى كتابسنجى و تحليل هم وازگگانى انجام

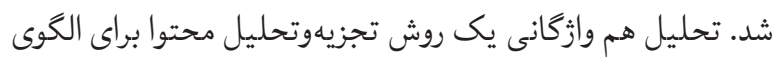

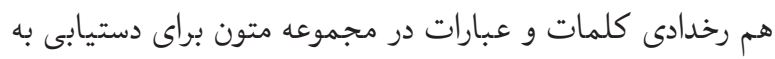
ارتباط ايدهها در حوزههاى موضوعى است( (Y)

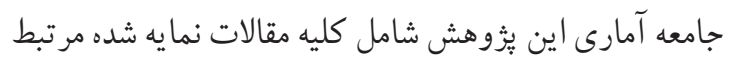

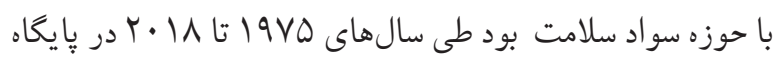
Medline: Medical Literature Analysis) اطلاعاتى مدلاين (and Retrieval System Online, or MEDLARS Online بودند كه با ابزار جستوجوى پاب مد (PubMed) در زانويه 19 إستخراج شدند.

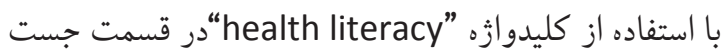
جوى بيشرفته تحت سر عنوانهاى موضوعى "MeSH Terms" و انتخاب ديتا بيس هاب مد؛ عناوين، نو يسند كان، نمايه مجلات

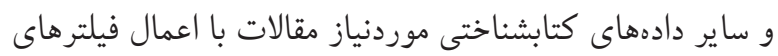

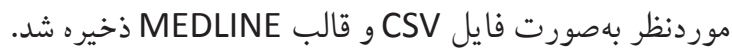
براى اطلاع از مهمترين موضوعات استناد كننده به مقالات حوزه سواد سلامت، نعاشت هم رخدادى واز كان و مصورسازى آنها با نها

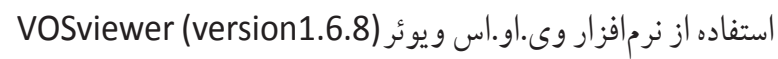
انجام شد. (http://www.vosviewer.com) vOSviewer است و مصورسازى شبكههاى كتابشناختى مبتنى بر فاصله را فر اهم

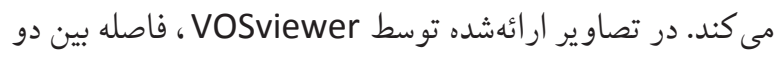

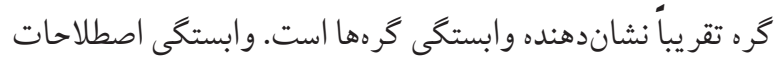

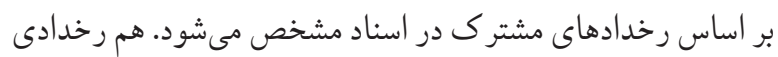

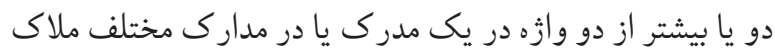

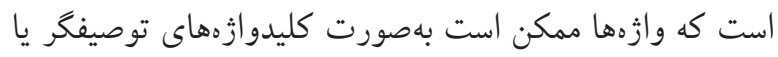
وازههاى متن باشند. مراحل تحليل در اين نرمافزار شامل سه مرحله: 


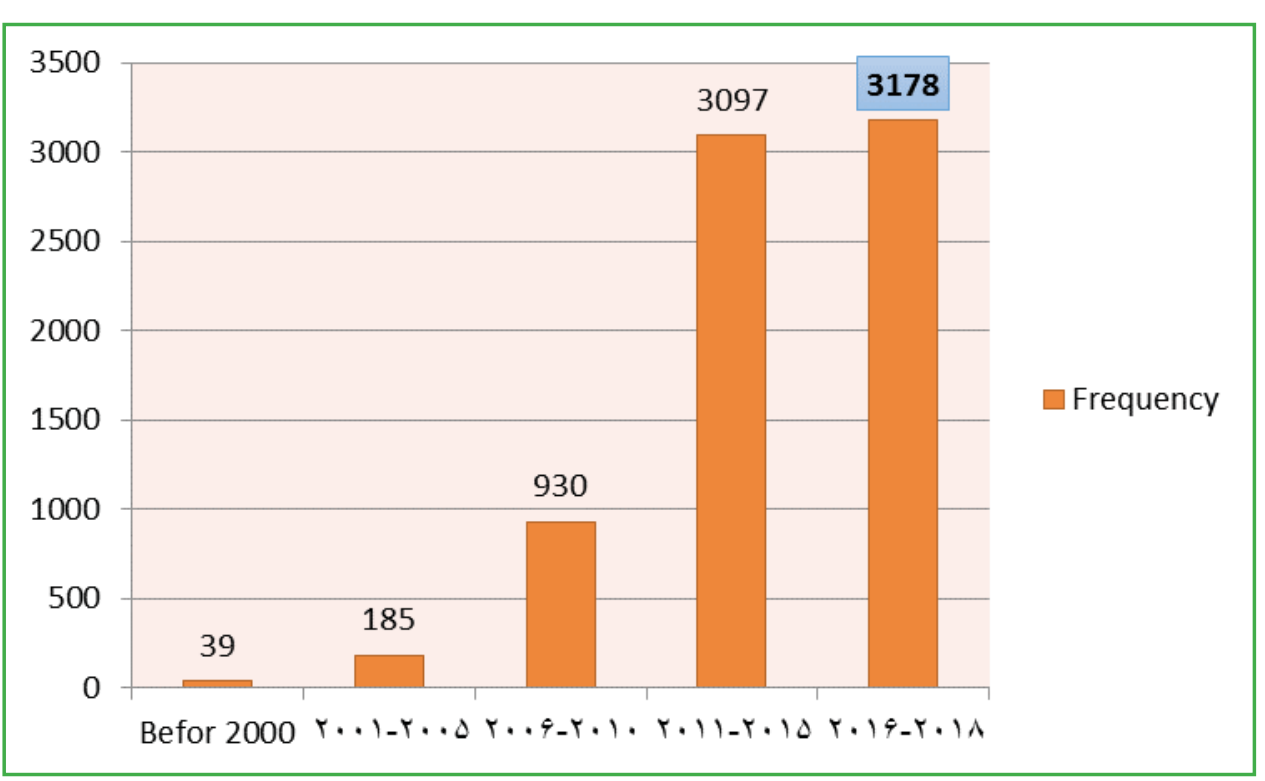

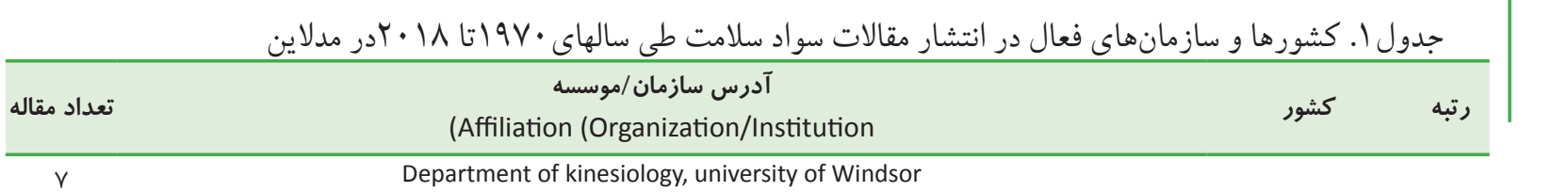

\begin{tabular}{|c|c|c|c|}
\hline$\Delta$ & Faculty of health, community and education, mount royal university, Calgary & \multirow{4}{*}{ Canada } & \multirow{4}{*}{1} \\
\hline q & School of health and human performance, Dalhousie university, halifa & & \\
\hline$\Delta$ & School of kinesiology and health studies, queen's university, Kingston & & \\
\hline q & School of physical and health education, nipissing university & & \\
\hline s & Center for health services research, Vanderbilt university medical, center Nashville, Tennessee & \multirow{4}{*}{ USA } & \multirow{4}{*}{ r } \\
\hline \& & $\begin{array}{l}\text { Division of plastic and reconstructive surgery, department of surgery, Beth Israel deaconess medical } \\
\text { center, Harvard medical school, Boston, Massachusetts }\end{array}$ & & \\
\hline 与 & School of nursing, Columbia university, new York & & \\
\hline 4 & $\begin{array}{l}\text { Center for clinical quality and implementation research, Vanderbilt university medical center, } \\
\qquad \text { Nashville, Tennessee }\end{array}$ & & \\
\hline 9 & Department of public health, university of Copenhagen, Copenhagen & \multirow{2}{*}{ Denmark } & \multirow{2}{*}{ r } \\
\hline 与 & Department of public health, Aarhus university, Aarhus & & \\
\hline 与 & Research department of clinical, educational and health psychology, university college London, London & \multirow{2}{*}{ UK } & \multirow{2}{*}{ r } \\
\hline 4 & School of healthcare, university of Leeds & & \\
\hline$\wedge$ & Institute of communication and health, university Della svizzera italiana, lugano & Switzerland & $\Delta$ \\
\hline$\Delta$ & Department of health communication, school of public health, the university of Tokyo & Japan & 与 \\
\hline$\Delta$ & Department of medical psychology, university medical center hamburg-eppendorf, Hamburg & Germany & $\checkmark$ \\
\hline$\Delta$ & Department of primary and community care, radboud university medical center, Nijmegen & \multirow{2}{*}{ Netherlands } & \multirow{2}{*}{$\wedge$} \\
\hline$\Delta$ & Department of public health, academic medical Centre, university of Amsterdam & & \\
\hline$\Delta$ & School of public health, Taipei medical university & Taiwan & 9 \\
\hline
\end{tabular}




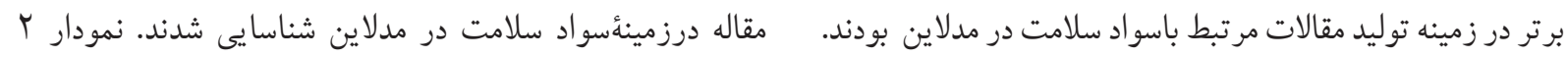

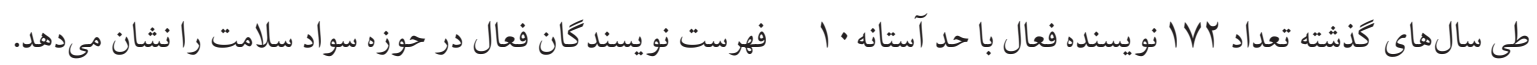

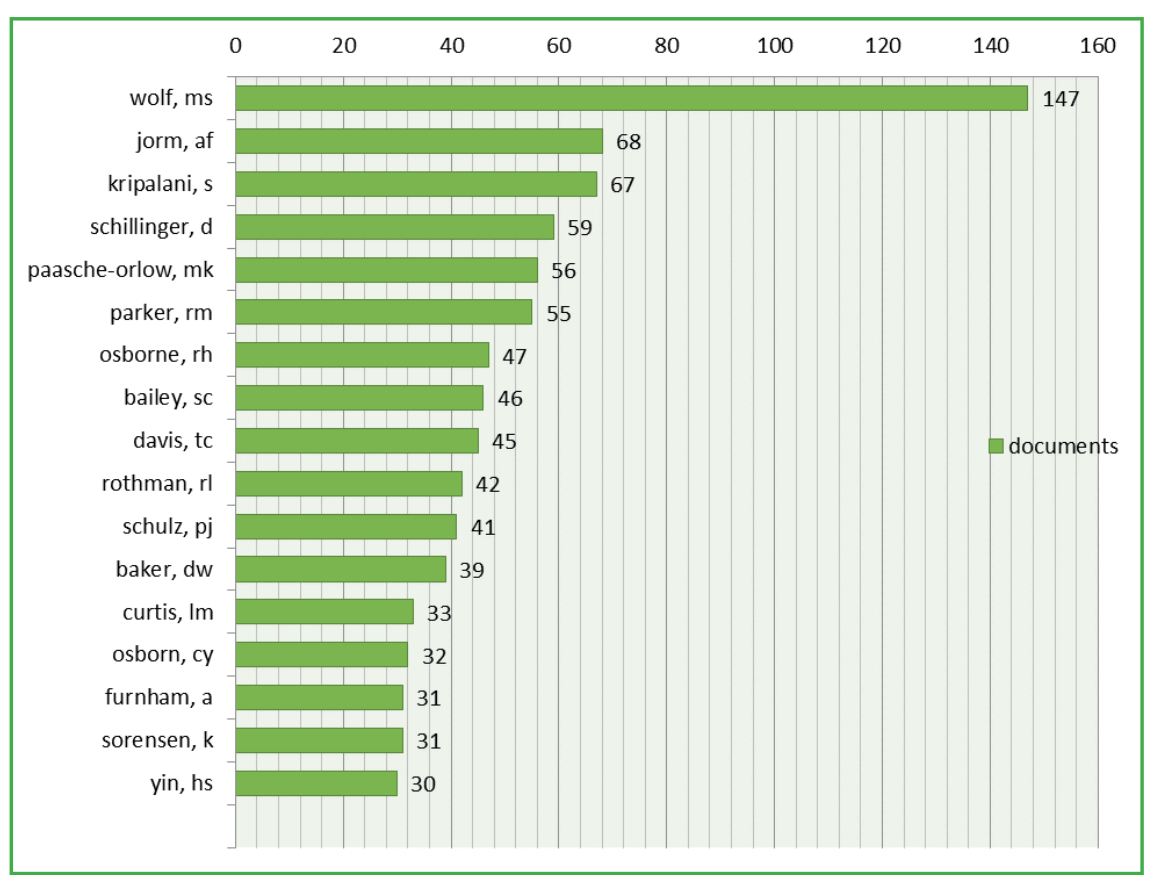

نمودار r. نويسند

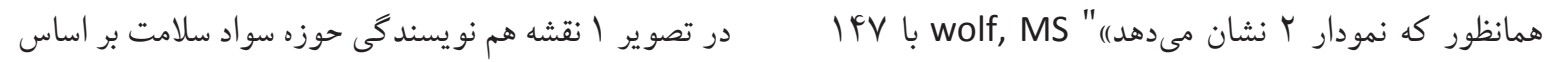

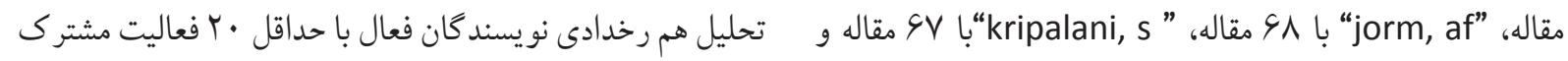
"schillinger, d”

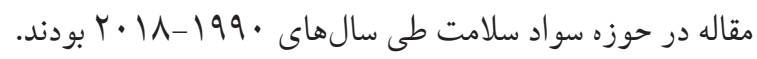

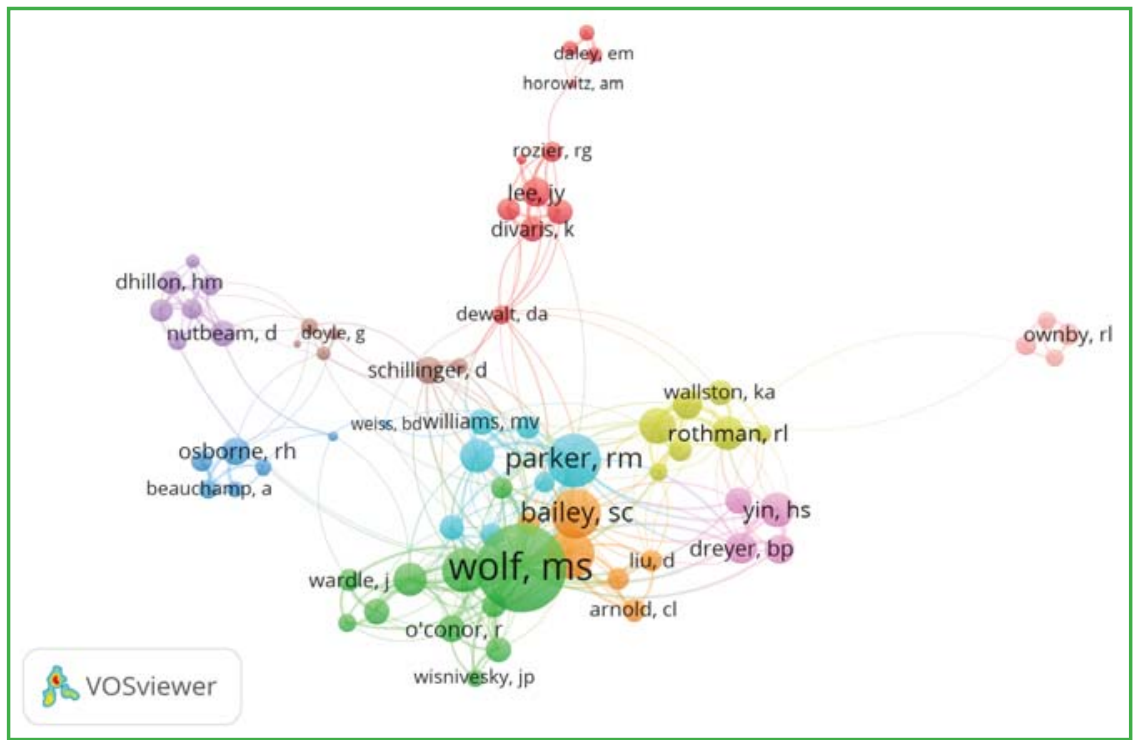

تصوير ا.نقشه هم رخدادى نويسند 
بسامد (فراوانى رخداد هم وازگ گانى) مقالات حوزه سواد سلامت در ياب

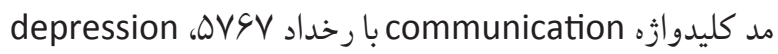

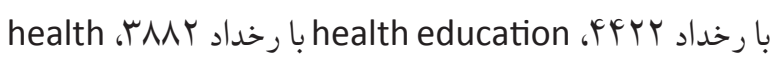
literacy

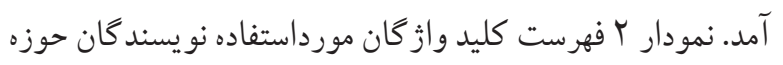

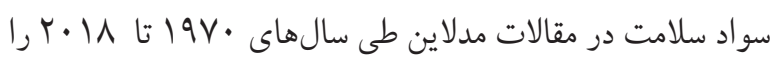

$$
\text { نشان مىدهد. }
$$

نتايج بهدست آمده بيانكر كستردگى نقشه فعاليت نو يسندگان و

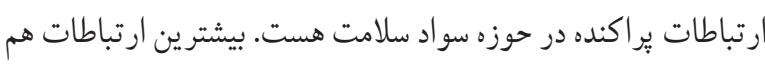
نو يسند گیى مر بوط به شبكه سبز (wolf, MS)، شبكه آبى (parker,rm) و شبكه نارنجى) (bailey, SC) نمايان است.

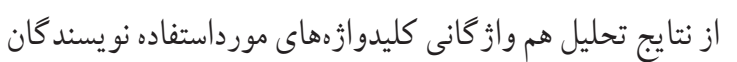

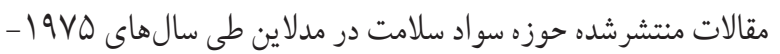

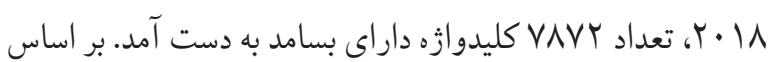

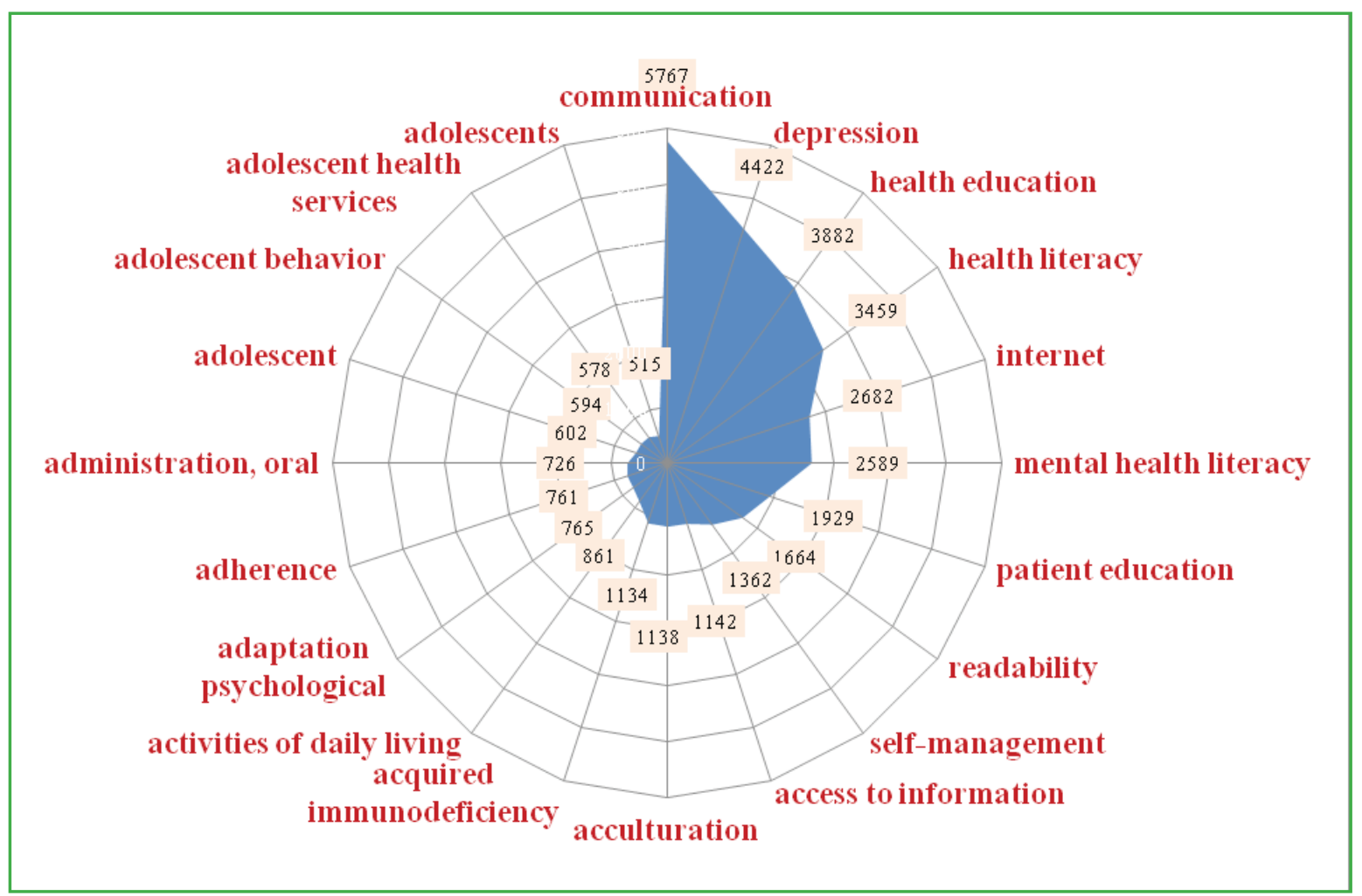

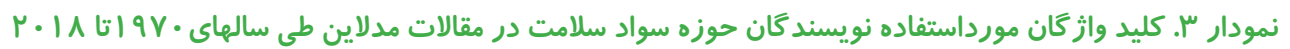

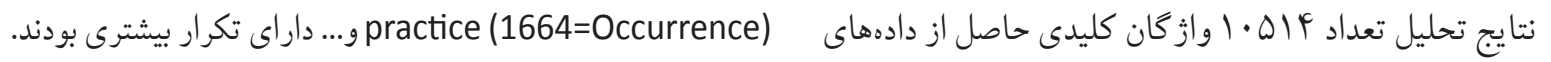

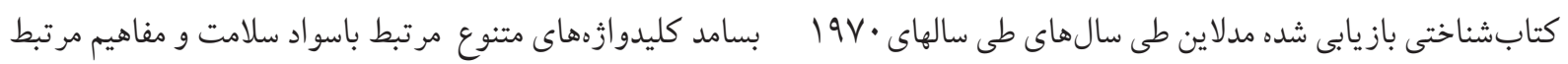

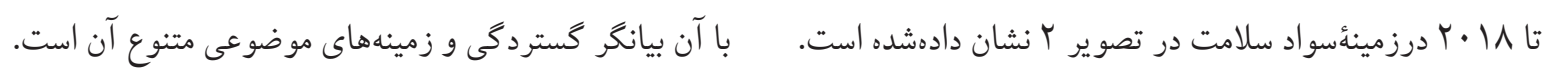
تجزيهوتحليل اصطلاحات و عبارات موضوعى (Terms) استخراجشده توسط از عنوان و جكيده متون مقالات حوزه سواد

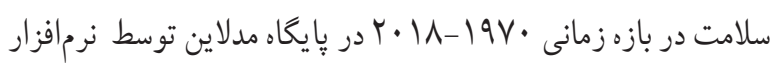

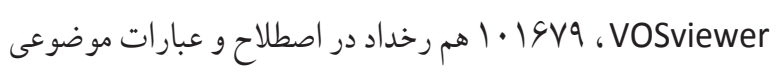
به دست آمد كه بر اساس آستانه رخداد •r إعبارات (Terms) بر اساس نتايج تصوير ب كليدوازه health literacy داراى رنغ قرمز و با بيشترين بسامد (4422=Occurrence) و به ترتيب كليدوازههاى. female (3882=Occurrence) male (3459=Occurrence) ، adult (2882=Occurrence)، aged (1929=Occurrence) ، health knowledge, attitudes, 


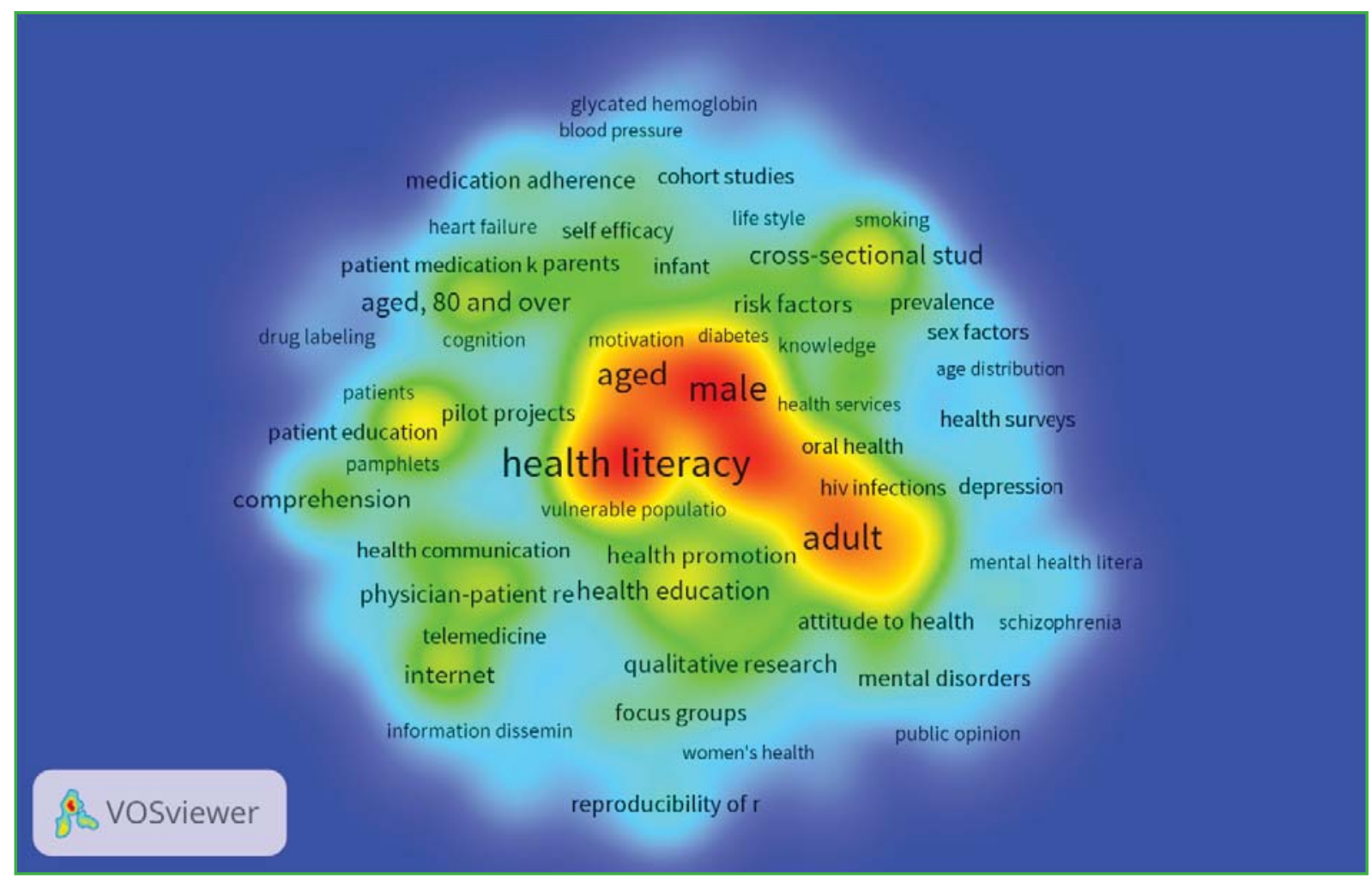

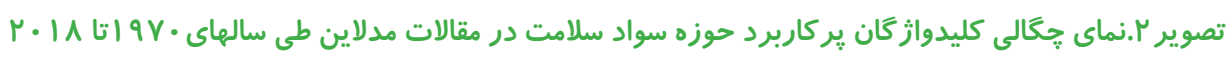

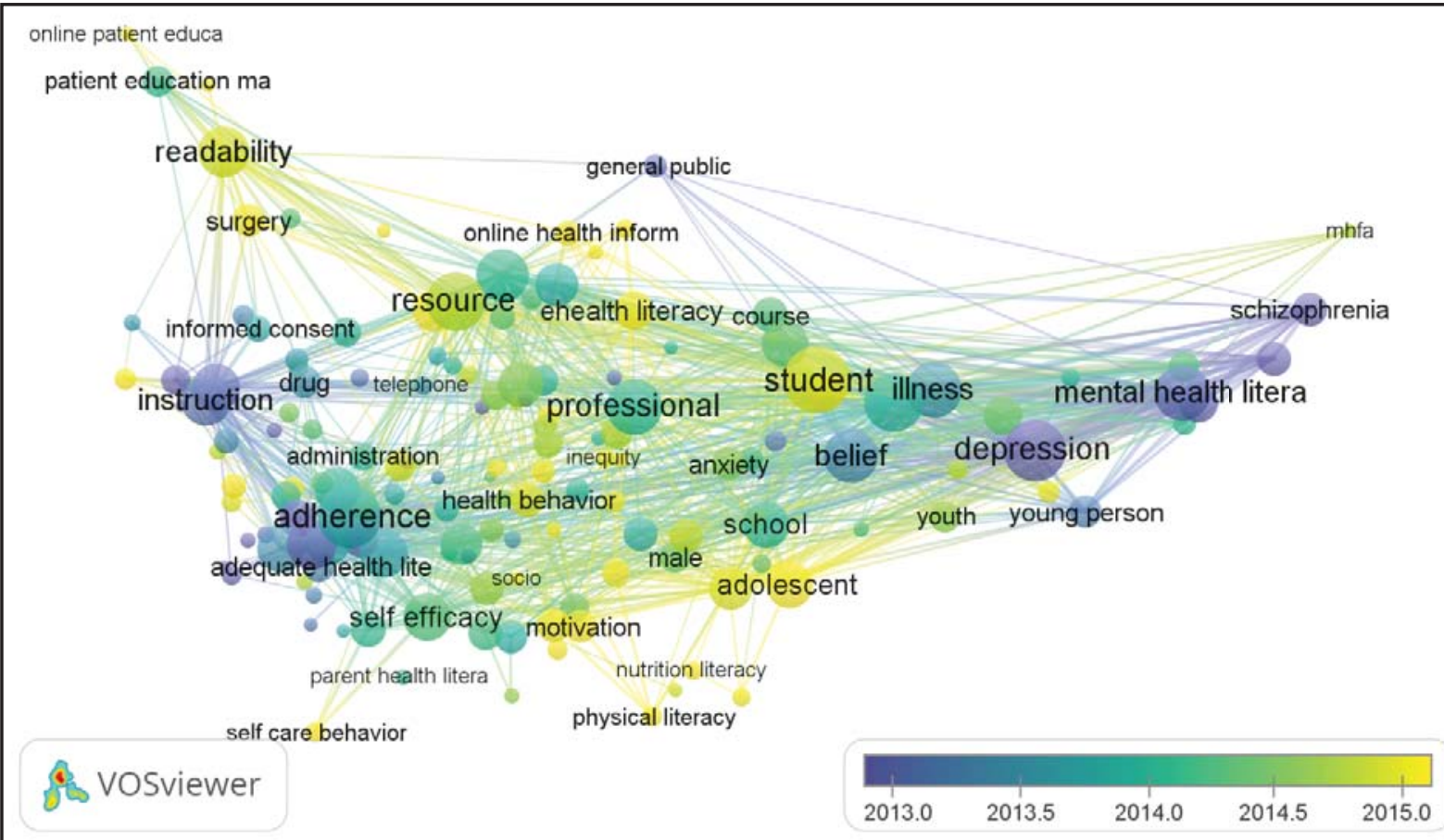

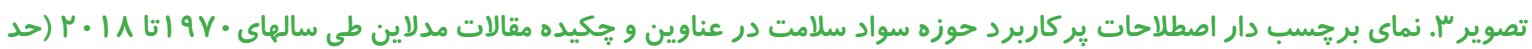
آستانه رخداد=• 
تحليل خوشهاى مهم ترين موضوعات محورى سواد سلامت در طى

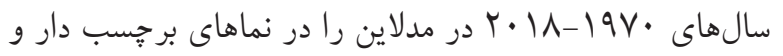

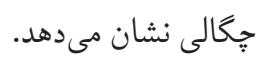

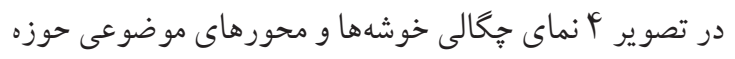

سواد سلامت در قالب 9 خوشه نشان دادهده است.

online patient educa

patient education ma

readability

surgery

online health inform

general public مرتبسازى كلمات و حذف اصطلاحات زائد (stop words) (كلمات مستقل از زمينه كه بار معنايى وابسته به دامنهى موردنظر

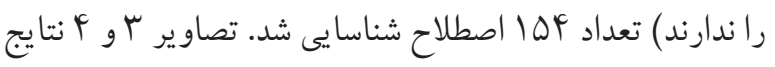

(Occurrence of Terms=30) قرار كرفت. اين عبارات با اعمال بيشفرض نرمافزار و تنظيمات

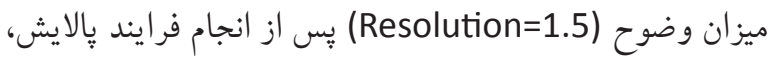

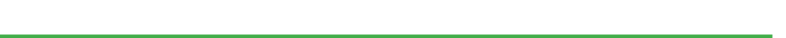

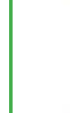

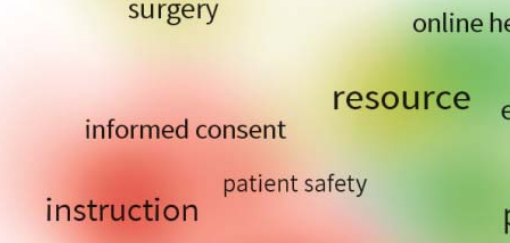

administration

ehealth literacy course

medical education

professional student illness

mental health litera

schizophrenia

inequity anxiety belief depression

adherence health behavior

adequate health lite

socio

school

youth young person

male

adolescent

self efficacy motivation

parent health litera

nutrition literacy

self care behavior

physical literacy

\section{VOSviewer}

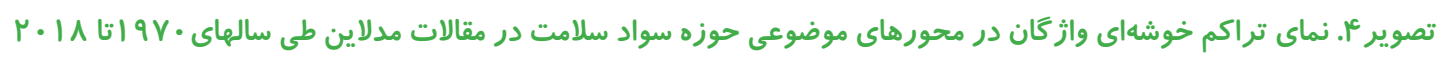

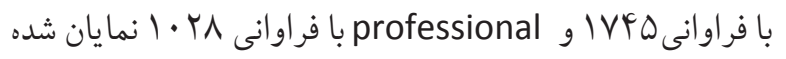

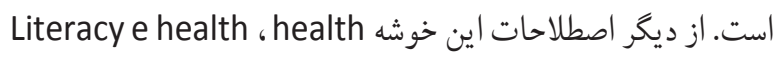

literacy

سومين خوشه كه بارنغ آبى نشان دادهشده است از ب آر اصطلاح

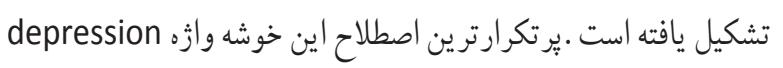

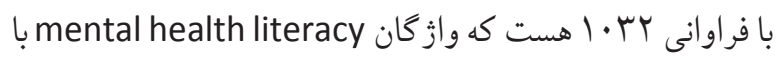

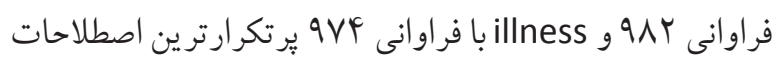

$$
\text { اين خوشه مىباشند. }
$$

در نمودار بأ فراوانى حوزههاى دانشى فعال مرتبط باسو اد سلامت
اولين و بزرگترين خوشه كه بارنگ قرمز مشخصشده از بو اصطلاح تشكيلشده است. در اين خوشه سه اصطلاح

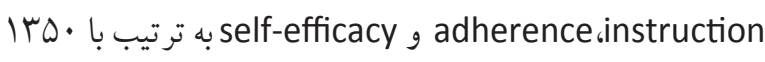

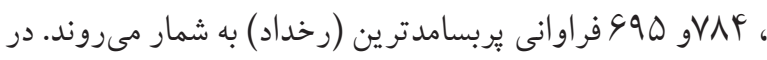
اين خوشه اصطلاحات ديخرى نظير income و و functional health literacy به جشم مى خورند. خوشه دوم كه بارنگ سبز متمايز شده است از ب ب اصطلاح

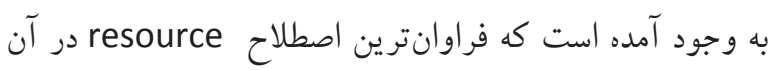


بر اساس خوشههاى بهدست آمده در مدلاين طى دههاى كذشته را بوده است. انتشارات علمى سواد سلامت روان و سواد سلامت در

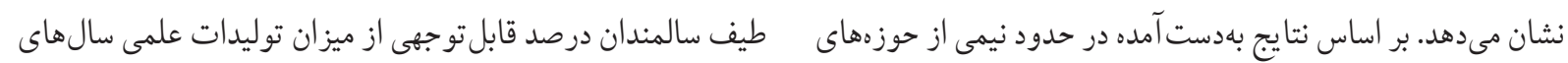

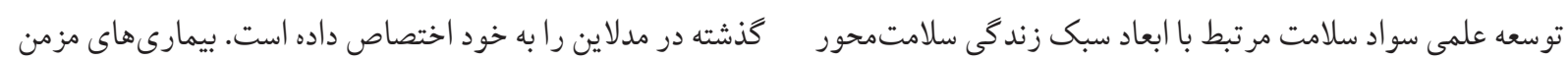

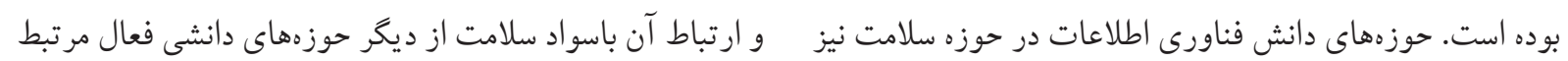

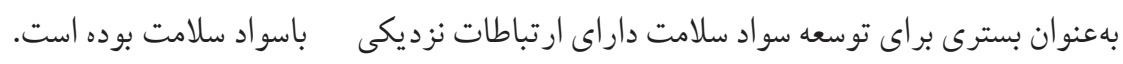

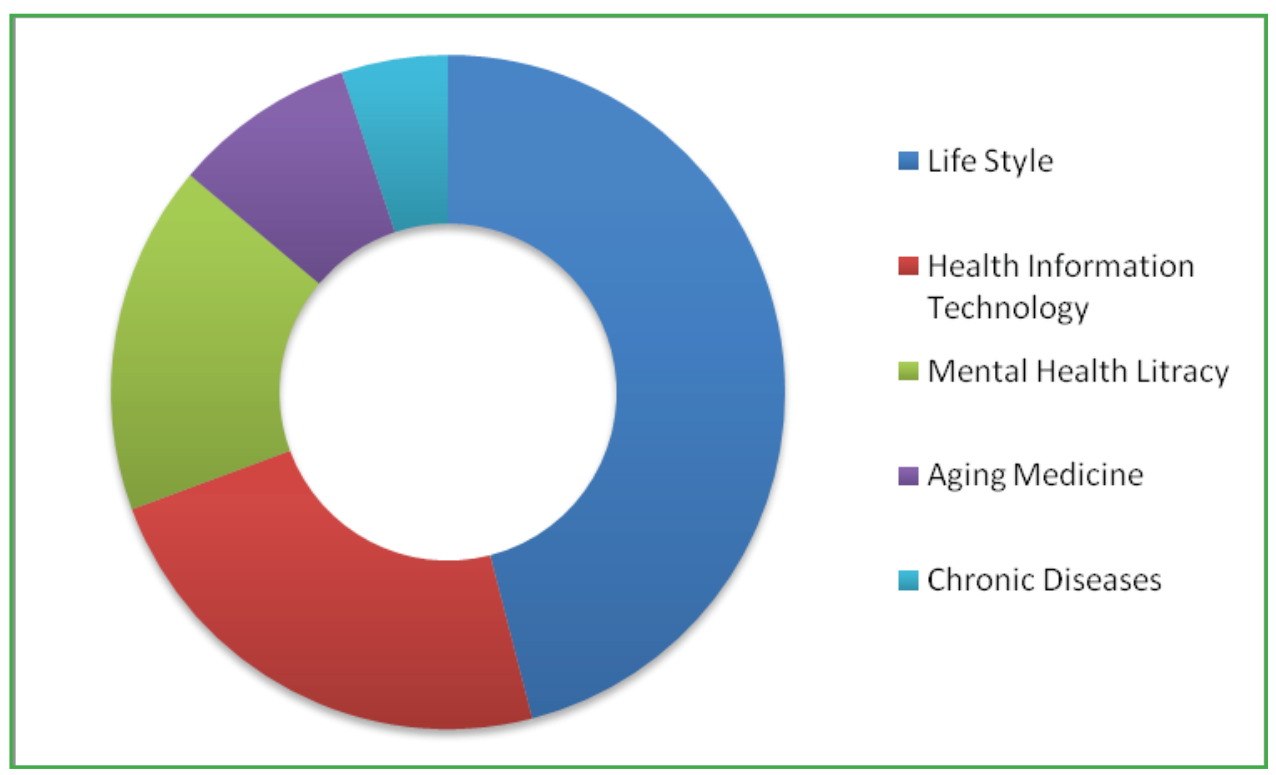

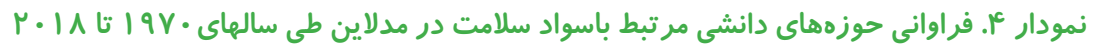

بحث و نتيجه گيرى

اين حوزه مىتوان به شناخت بيشتر سواد سلامت بهعنوان موضوع

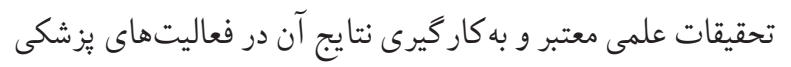

$$
\text { و آموزشى اشاره نمود. }
$$

همجنِين سو اد سلامت بهعنوان يـكى از مباحث جهانى است( (YY).

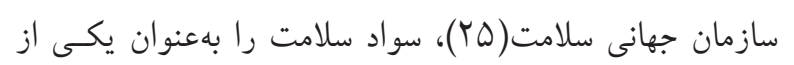

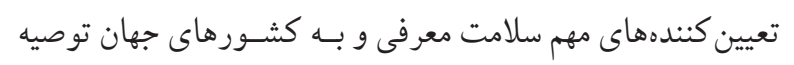

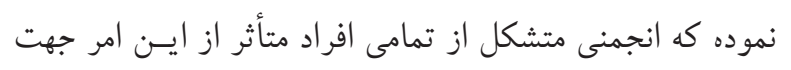

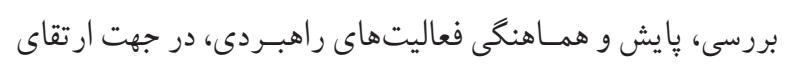

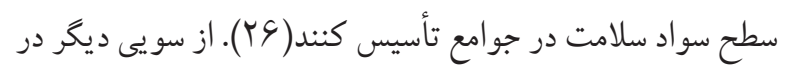

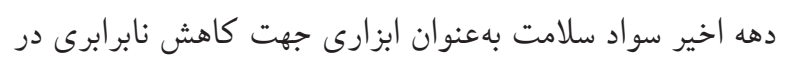

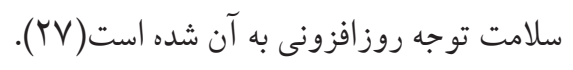

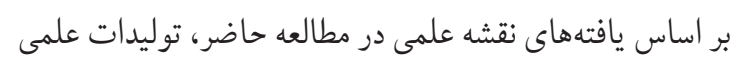

مطالعه حاضر باهدف بررسى روند و ترسيم نقشه علم سواد سلامت بر اساس تحليل هم رخدادى وازگًان موضوعى سواد سلامت در يايكاه علمى و استنادى مدلاين انجام شد. نتايج مطالعه نشان داد، رشد توليدات علمى مربوط به حوزه إندان

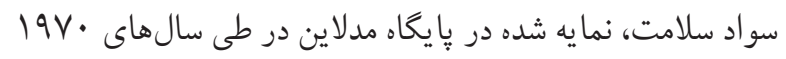

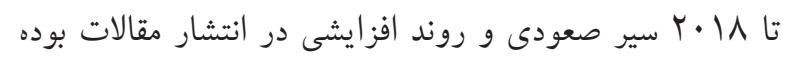

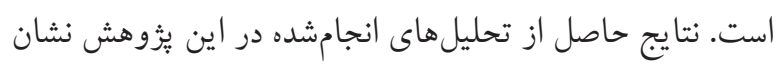
داد كه ساختار حوزههاى موضوعى در زمينه سواد سلامت در طول

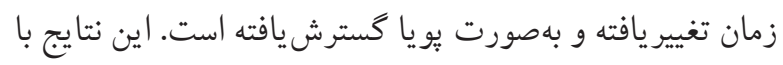
يافتهاى رشد توليدات علمى در ساير حوزههاى سلامت ازجمله

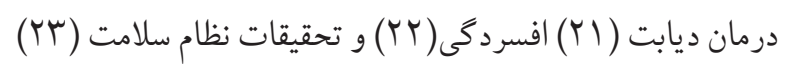
همسو است. ازجمله دلايل روند رو به رشد توليدات علمى در 
بسيار بر اكنده است. اين نتيجه نشان مىدهد كه محققان بايد در

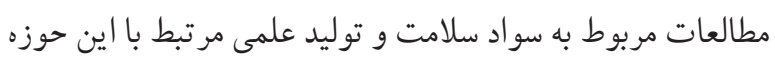

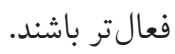
از عمده دلايل جهت كيرى مطالعات منتشره شده در كشورهايى مانند ايلاتمتحده و كانادا مى توان به عواملى متأثر از افزايش

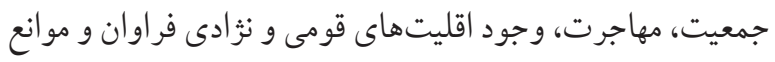

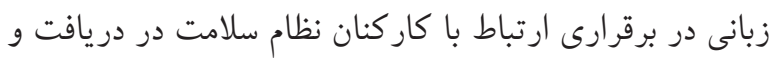
لمرهمندى از خدمات و سرويسهاى سلامتى اشاره نمود.

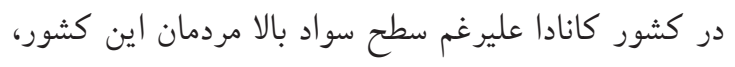

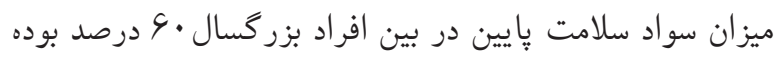

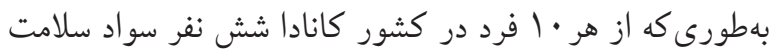

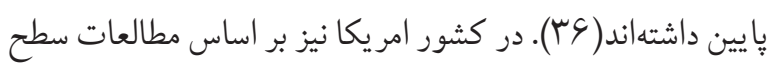

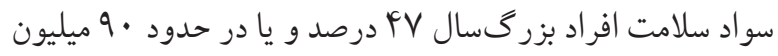

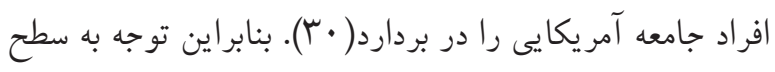
سواد سلامت با افزايش توليدات علمى در اين حوزه با يافتههاى دراي اين مطالعه مطابقت دارد. يافتهاى حاضر نشان داد برخى از مطالعات در كشورهاى

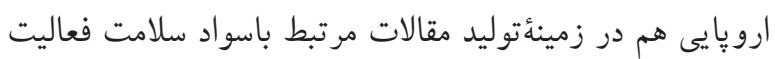

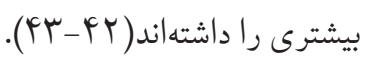

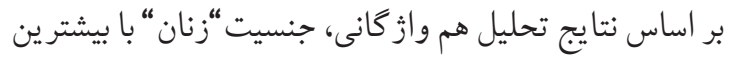

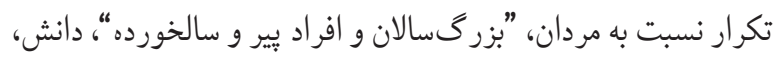
نكرش و عملكرد سلامتى داراى تكرار بيشترى بودند.

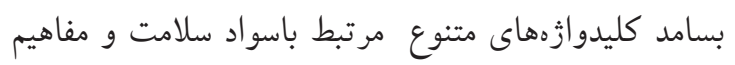

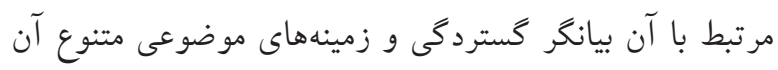

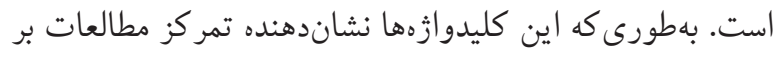

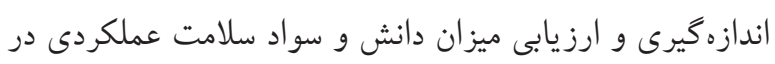
كروههاى خاص ازجمله زنان و در سنين خاص ازجمله سالمندان

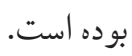
زنان بهعنوان كروهاى آسيبذيذير جامعه به دليل شرايطى

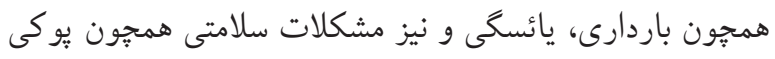
استخوان نيازمند توجهات خاص بهداشتى هستند.(YV). هميجنين نتايج

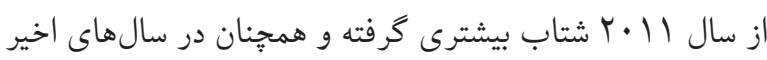

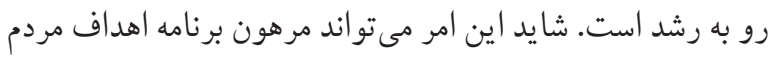

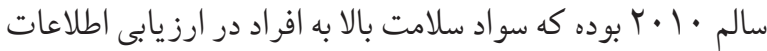

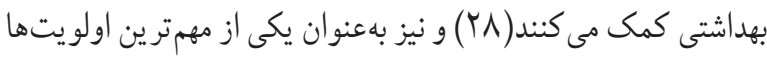

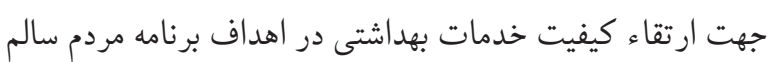

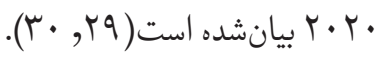

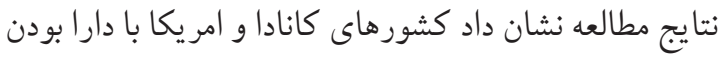

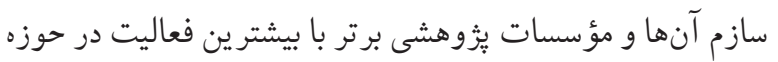
سواد سلامت در رتبههاى اول و دوم قرار داشته و بيشتر ين توليدات

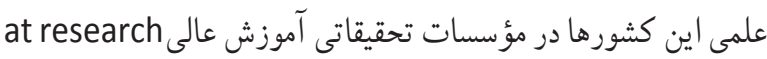
institutions of higher education اين اطلاعات مىتواند براى محققين جهت شناسايى و مشاركت

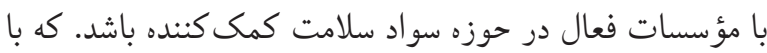

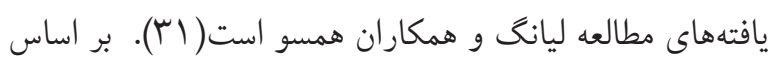

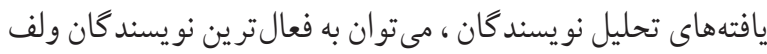

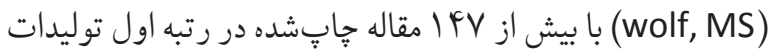
علمى در حوزه سواد سلامت اشاره نمود. در مطالعه ليانگ و همكاران

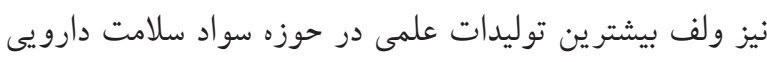

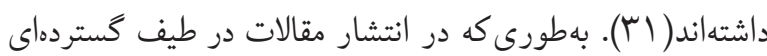
از موضوعات درزمينٔسواد سلامت، مداخلات سواد دارويى و ارتباط

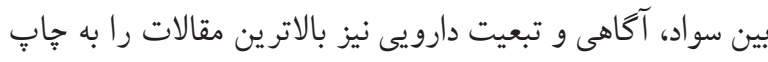

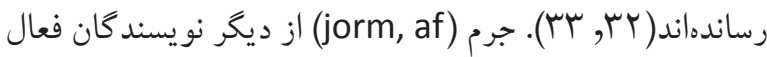

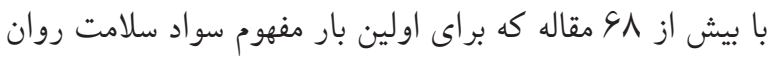

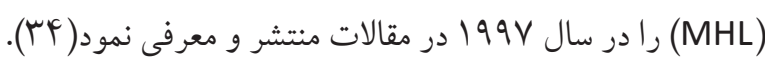
شبكه هم نويسند سى سواد سلامت، داراى ده خوشه اصلى نويسند كان

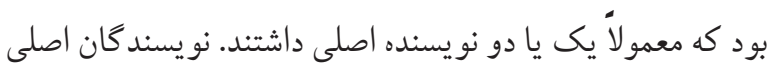

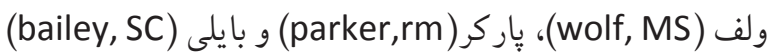

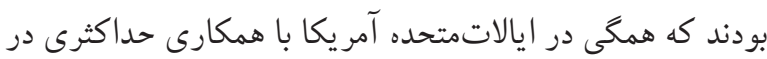

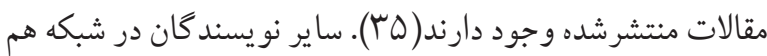
نو يسندگى بهصورت فردى بودند. بر اساس نتايج تحليل شبكههاى اجتماعى، مشخص شد كه همكارى تحقيقاتى درزمينئسواد سلامت 
ارتباطى شفاف براى ارائه اطلاعات و آموزش به بيماران دارند، اما

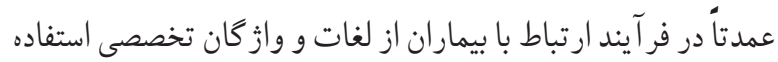

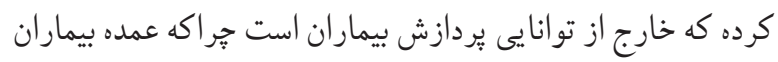
با اصطلاحات يزشكى نآشنا بوده و تمركز بر اطلاعات ارائهشده

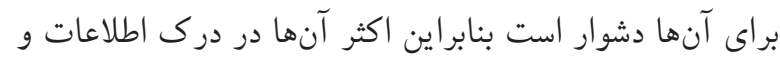

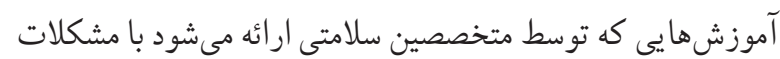

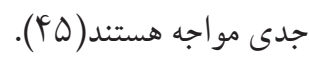

نتايج تحليل خوشهاى سواد سلامت بيانكر ارتباط اصطلاحات

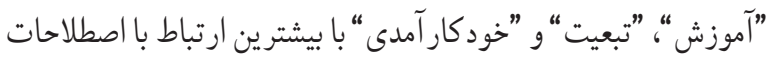

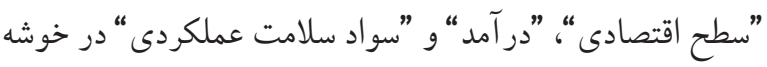
اول بود. اين خوشه بيانكر تمر كز سواد سلامت بر آموزش، بيشكيرى سورى

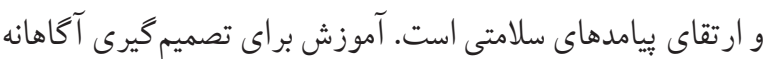

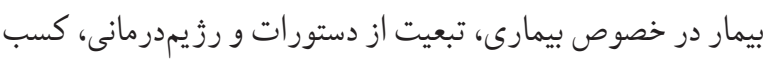

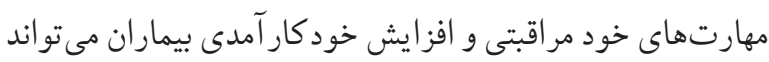
كمك كننده باشد (FV, FY (F)).

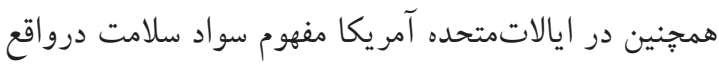
براى توصيف و توضيح ارتباط بين سواد سلامت بيماران و توانايى

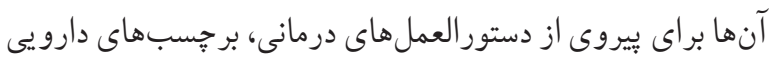

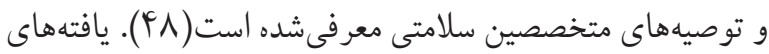

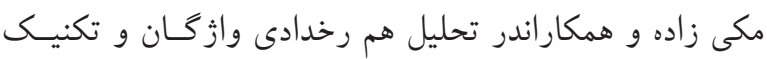
تحليـل شبكهاى مقالات حوزه افسردگى نيز نشان داد كه زمينه هاى موضوعى تبعيت و يا يبندى به درمان از مهم تر ين زمينههاى نوظهور در حوزه افسردگى است(Y (Y). كه بامطالعه حاضر همراستا است.

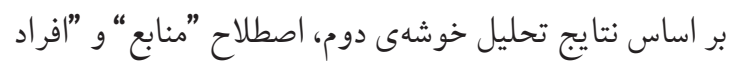

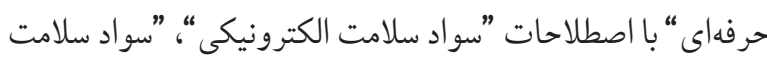

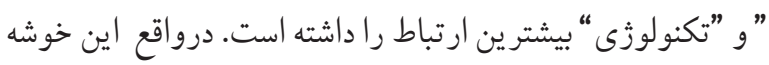
بر سو اد سلامت ارتباطى يعنى تو انايى فرد در شناسايى منابع معتبر و

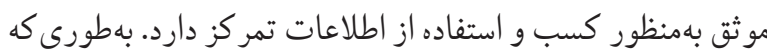

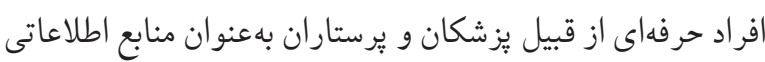

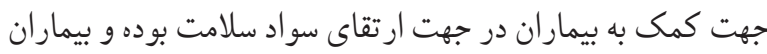
تمايل دارند جهت ارتقاى سطح دانش بهداشتى خود از ساير منابع و
مطالعهاى بيانكر سواد سلامت محدود در وب درصد از بزرگسالان

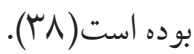

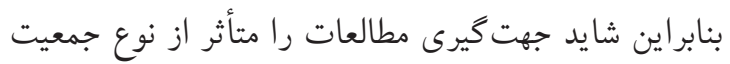
و مسائل بهداشتى مواجهه آنان و كانون توجه اكثر مطالعات در كروههاى آسيب يذير دانست. بهطورى كه نتايج مطالعهاى نشان داد سو اد سلامت كم بهوفور

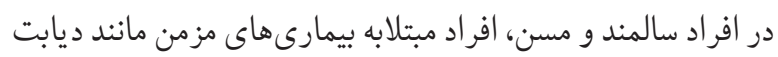

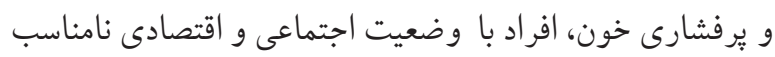

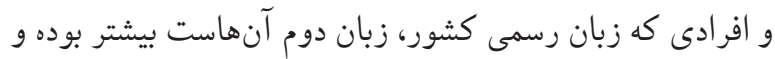

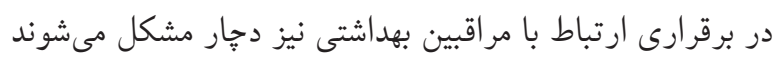

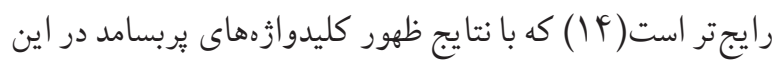
مطالعه مطابقت دارد. ظهور كليدوازه "تكنولوزى"، "اينترنت“ بهعنوان منبع كسب دارد

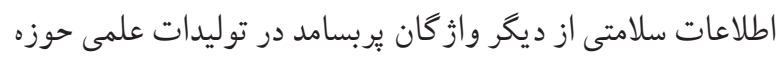

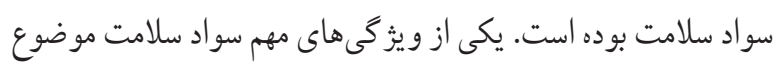

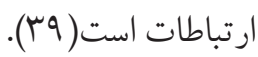

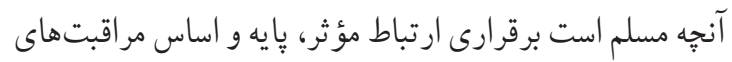
بهداشتى بيمار محور را تشكيل مىدهد، سواد سلامت مؤلفهاى كليدى براى ايجاد ارتباطى اثربخش بين بيماران و متخصصين

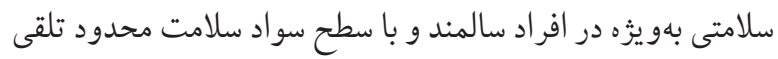

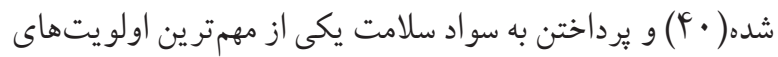

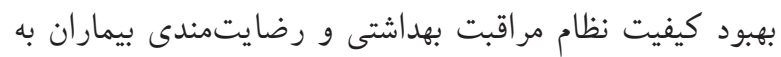

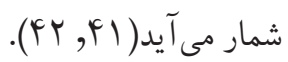
طبق مطالعهاى اينترنت منبع خوبى از اطلاعات مرتبط بهسلامت التات است. حدود نيمى از افرادى كه به دنبال اطلاعات بهداشتى در اينترنت

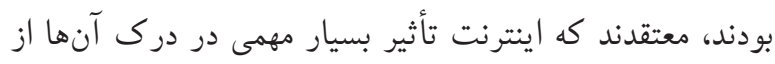

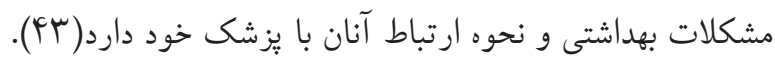

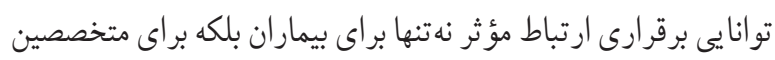

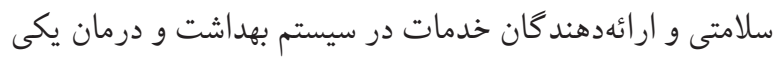
از مهمتر ين و اصلى ترين مهارتهاى لازم محسوب مىشود (FF). ارائهدهندكان خدمات بهداشتى و درمانى تمايل به برقرارى 
مهـم، تحليـل خوشهاى دانشى و محورهاى موضوعى حــوزن

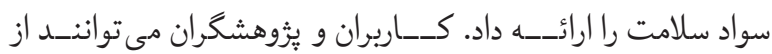
وضـعيت يزوهشـى و موضـوعى اين حوزه آكاهى يابند. البته در

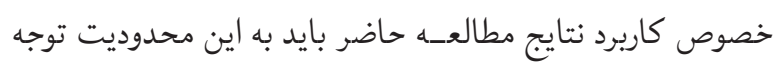

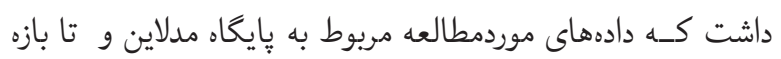

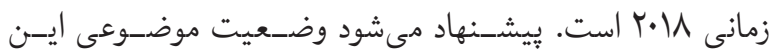
ح-وزه در ساير پايخاههاى داده نيز انجام يذيرد.

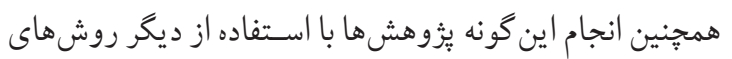
علمسنجى مانتــد تحليـل اسـتنادى و ترسـيم نقشـهـ علمسى مرتبط با آن توصيه مىشود.

با توجه به ماهيت ميان رشتهاى سو اد سلامت با حوزههاى آموزش، تون،

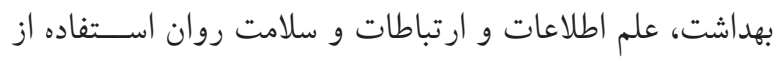

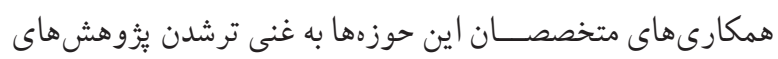

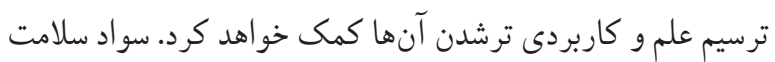
ديجيتال، علاوه بر بيمارىهاى مزمن و سرطان، سواد سلامت در برد

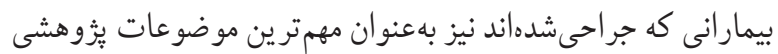
در آينده خواهد بود. تقدير و تشكر: مقاله حاضر بدون حمايت مالى از موسسه و يا ينا سازمان انجام شده است، نويسندكان از آقاى دكتر سيد مصطفى حكيم زاده براى همكارى ارزشمندشان در مطالعه تشكر ويثه مى كنند. تضاد منافع: نويسندگان اظهار داشتند كه تضاد منافعى وجود ندارد

\section{References}

1. Batooli Z, Fahimnia F. The Analysis and Review of the Literatures in the field of Game in libraries. Journal of Studies in Library and Information Science. 2018;10(25):129-62.

2. Forghani T, Ahmadian M, Rezaeisharif F, Ahadi M. Survey of Health Literacy during pregnancy and Its Relationship with Prenatal Care. Journal of Health Literacy. 2021;6(1):20-30.

3. Nejatian M, Tehrani H, Momeniyan V, Jafari A. A modified version of the mental health literacy scale (MHLS) in Iranian people. BMC psychiatry. 2021;21(1):1https://doi.org/10.1186/s12888-021-03050-3 PMid:33485306 PMCid:PMC7824912

4. Sheridan SL, Halpern DJ, Viera AJ, Berkman ND, Donahue KE, Crotty K. Interventions for individuals
تكنولوزى هاى موجود و در دسترس ازجمله اينترنت جهت كسب

اطلاعات خود استفاده كنند(19). نتايج تحليل خوشهى سوم، بهاصطلاح "|فسردكى" بهعنوان مركزيت يكى از خوشههاى موضوعى حوزه سواد سلامت اشاره

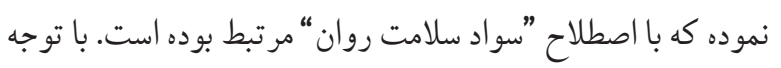

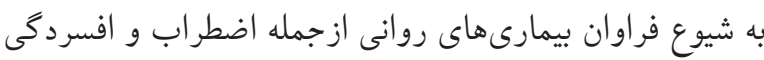

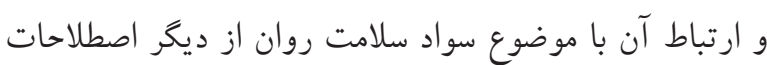
يربسامد در يافته هاى مطالعه بوده است.

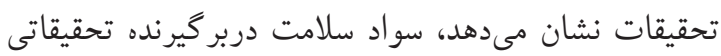

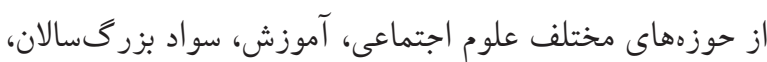
كتابدارى و يرستارى سلامت روان هست (YT)

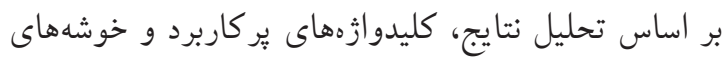

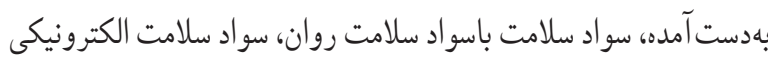
و سو اد سلامت عملكردى مر تبط است. سو اد سلامت بيشتر ين بيوندها

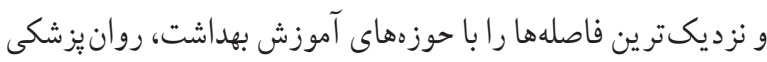
و روانشناسى، بهداشت عمومى، علوم اطلاعات و ارتباطات داشته

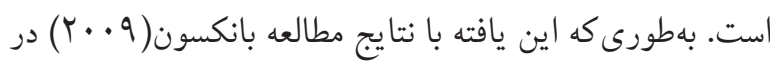

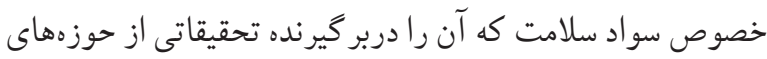

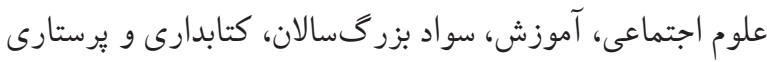
دانست( • (D) هم خوانى داشته است.

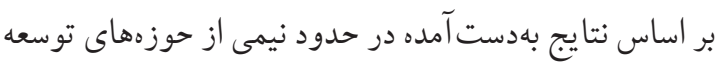
علمى سواد سلامت مرتبط با ابعاد سبك زندكى سلامت محور بودهد

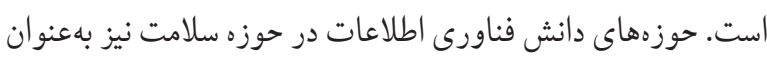
بسترى براى توسعه سواد سلامت داراى ارتباطات نزديكى بودهد

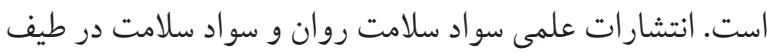

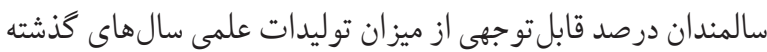

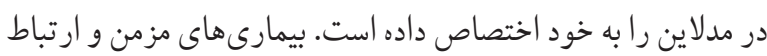

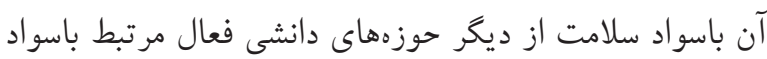

$$
\text { سلامت بوده است. }
$$
نتيجه گَيرى: نتايج اين مطالعه بيانكر وضعيت جارى توليدات علمى،

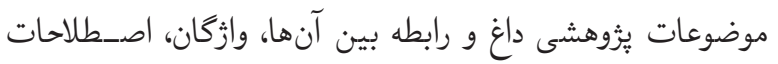


with low health literacy: a systematic review. Journal of health communication. 2011;16(sup3):30-54. https://doi.org/10.1080/10810730.2011.604391 PMid:21951242

5. Izadi L, Taghdisi MH, Ghadami M, Delavar A, Sarokhani B. Identification of Effective Factors Decision Making in Crisis in Media rganization: A Systematic Review with Emphasis on Media literacy in Health Crisis (CORONA PANDEMIC. Iranian Journal of Health Education and Health Promotion. 2020;8(4):390-406. https://doi.org/10.29252/ijhehp.8.4.390

6. Charoghchian Khorasani E, Tavakoly Sany SB, Tehrani H, Doosti H, Peyman N. Review of Organizational Health Literacy Practice at Health Care Centers: Outcomes, Barriers and Facilitators. International journal of environmental research and public health. 2020;17(20):7544. https://doi.org/10.3390/ijerph 17207544 PMid:33081335 PMCid:PMC7589923

7. Andrade I, Silva C, Martins AC. Application of the Health Literacy INDEX on the development of a manual for prevention of falls for older adults. Patient education and counseling. 2017;100(1):154-9. https://doi.org/10.1016/j.pec.2016.07.036 PMid:27516436

8. Van Hoa H, Giang HT, Vu PT, Van Tuyen D, Khue PM. Factors associated with health literacy among the elderly people in Vietnam. BioMed research international. 2020;2020. https://doi.org/10.1155/2020/3490635 PMid:32309429 PMCid:PMC7139882

9. Lee Y-M, Yu HY, You M-A, Son Y-J. Impact of health literacy on medication adherence in older people with chronic diseases. Collegian. 2017;24(1):11-8. https://doi.org/10.1016/j.colegn.2015.08.003 PMid:29218957

10. Tehrani H, Olyani S. The Effect of an Education Intervention on Mental Health Literacy among Middle School Female Students. Journal of Health Literacy. 2021;5(4):41-7

11. Baker DW, Gazmararian JA, Williams MV, Scott T, Parker RM, Green D, et al. Functional health literacy and the risk of hospital admission among Medicare managed care enrollees. American journal of public health. 2002;92(8):1278-83. https://doi.org/10.2105/AJPH.92.8.1278 PMid:12144984 PMCid:PMC1447230

12. Schillinger D, Grumbach K, Piette J, Wang F, Osmond D, Daher C, et al. Association of health literacy with diabetes outcomes. Jama. 2002;288(4):475-82. https://doi.org/10.1001/jama.288.4.475 PMid:12132978

13. Howard DH, Sentell T, Gazmararian JA. Impact of health literacy on socioeconomic and racial differences in health in an elderly population. Journal of general internal medicine. 2006;21(8):857-61. https://doi.org/10.1111/j.1525-1497.2006.00530.x PMid:16881947 PMCid:PMC1831584

14. Kutner M, Greenburg E, Jin Y, Paulsen C. The Health Literacy of America's Adults: Results from the 2003 National Assessment of Adult Literacy. NCES 2006-483. National Center for Education Statistics. 2006.

15. Jalali S, Keshvari M, Soleymani MR. Fitness informationseeking behavior among female university students: A qualitative study. Plos one. 2020;15(8):e0237735. https://doi.org/10.1371/journal.pone.0237735 PMid:32804937 PMCid:PMC7430743

16. Chang $X$, Zhou X, Luo L, Yang C, Pan H, Zhang S. Hotspots in research on the measurement of medical students' clinical competence from 2012-2016 based on coword analysis. BMC medical education. 2017;17(1):1-6. https://doi.org/10.1186/s12909-017-0999-8 PMid:28899380 PMCid:PMC5596946

17. Dai S, Duan $X$, Zhang $W$. Knowledge map of environmental crisis management based on keywords network and co-word analysis, 2005-2018. Journal of Cleaner Production. 2020;262:121168. https://doi.org/10.1016/j.jclepro.2020.121168

18. Ravikumar S, Agrahari A, Singh SN. Mapping the intellectual structure of scientometrics: A coword analysis of the journal Scientometrics (20052010). Scientometrics. 2015;102(1):929-55. https://doi.org/10.1007/s11192-014-1402-8

19. Biranvand A, Samadbeik $M$, Khasseh A. Mapping of Knowledge Structure in the Field of Health Information Management and Technology: A Co-Word Analysis. Depiction of Health. 2020;11(2):117-36. https://doi.org/10.34172/doh.2020.13

20. De Bellis N. Bibliometrics and citation analysis: from the science citation index to cybermetrics: scarecrow press; 2009.

21. Makkizadeh F HA, Hosininasab S, Keikhaee F. The Study of Thematic Structure of Documents related to the Treatment of Diabetes Mellitus, Type 2 in PubMed from 2005-2014. journal of Health Administration ,. 2016;19(64):43-55[persian].

22. Makkizadeh F HA, Hosininasab S, Soheili F. . Thematic Analysis and Scientific Mapping of Papers related to Depression Therapy in PubMed. . J Health Adm. 2016;19(65):51-63.

23. Yao $Q$, Chen K, Yao L, Lyu P-h, Yang T-a, Luo $F$, et al. Scientometric trends and knowledge maps of global health systems research. Health research policy and systems. 2014;12(1):26. https://doi.org/10.1186/1478-4505-12-26 PMid:24903126 PMCid:PMC4065315

24. Nutbeam D, Kickbusch I. Advancing health literacy: a global 
challenge for the 21st century. Oxford Univ Press; 2000. https://doi.org/10.1093/heapro/15.3.183

25. WHO. Coronavirus disease 2019 (COVID-19) Situation. WHO. Coronavirus disease 2019 (COVID-19) Situation Report-98. https:// www.who.int/docs/default-source/ coronaviruse/situation-reports/20200427-

sitrep-98-covid-19.pdf?sfvrsn1\%490323472_4. [Accessed 28 April 2020]. Accessed; 2020.

26. Marmot M, Friel S, Bell R, Houweling TA, Taylor S, Health CoSDo. Closing the gap in a generation: health equity through action on the social determinants of health. The lancet. 2008;372(9650):1661-9. https://doi.org/10.1016/S0140-6736(08)61690-6

27. $W u A D$, Begoray $D L$, MacDonald $M$, Wharf Higgins J, Frankish J, Kwan B, et al. Developing and evaluating a relevant and feasible instrument for measuring health literacy of Canadian high school students. Health promotion international. 2010;25(4):444-52. https://doi.org/10.1093/heapro/daq032 PMid:20466776

28. Sondik EJ, Huang DT, Klein RJ, Satcher D. Progress toward the healthy people 2010 goals and objectives. Annual review of public health. 2010;31:271-81 4 p folliwng 81 . https://doi.org/10.1146/annurev. $\mathrm{publh}$ e a It h. 01228009.1033613 PMid:20070194

29. Koh HK, Piotrowski JJ, Kumanyika S, Fielding JE. Healthy people: a 2020 vision for the social determinants approach. Health Education \& Behavior. 2011;38(6):551-7. https://doi.org/10.1177/1090198111428646 PMid:22102542

30. Parker R, Ratzan SC. Health literacy: a second decade of distinction for Americans. Journal of health communication. 2010;15(S2):20-33. https://doi.org/10.1080/10810730.2010.501094 PMid:20845190

31. Liang C, Luo A, Zhong Z. Knowledge mapping of medication literacy study: A visualized analysis using CiteSpace. SAGE open medicine. 2018;6:2050312118800199. https://doi.org/10.1177/2050312118800199 PMid:30245817 PMCid:PMC6144508

32. Wolf MS, Davis T, Arozullah A, Penn R, Arnold $C$, Sugar $M$, et al. Relation between literacy and HIV treatment knowledge among patients on HAART regimens. AIDS care. 2005;17(7):863-73. https://doi.org/10.1080/09540120500038660 PMid:16120503

33. Wolf MS, Davis TC, Curtis LM, Bailey SC, Knox JP, Bergeron $A$, et al. A patient-centered prescription drug label to promote appropriate medication use and adherence. Journal of general internal medicine. 2016;31(12):1482-9. https://doi.org/10.1007/s11606-016-3816-x
PMid:27542666 PMCid:PMC5130952

34. Jorm AF, Korten AE, Jacomb PA, Christensen $H$, Rodgers B, Pollitt P. "Mental health literacy": a survey of the public's ability to recognise mental disorders and their beliefs about the effectiveness of treatment. Medical journal of Australia. 1997;166(4):182-6. https://doi.org/10.5694/j.1326-5377.1997.tb140071.x PMid:9066546

35. Bailey SC, O'Conor R, Bojarski EA, Mullen R, Patzer $R E$, Vicencio $D$, et al. Literacy disparities in patient access and health-related use of Internet and mobile technologies. Health expectations : an international journal of public participation in health care and health policy. 2015;18(6):3079-87. h tt p s: / / d o i . org / 10.1111 / h ex.12294 PMid:25363660 PMCid:PMC4417455

36. Murray T, Hagey J, Willms D, Shillington R, Desjardins R. Health literacy in Canada: a healthy understanding. 2008.

37. Ferguson B. Health literacy and health disparities: The role they play in maternal and child health. Nursing for women's health. 2008;12(4):286-98. https://doi.org/10.1111/j.1751-486X.2008.00343.x PMid:18715376

38. Shieh C, Halstead JA. Understanding the impact of health literacy on women's health. Journal of Obstetric, Gynecologic, \& Neonatal Nursing. 2009;38(5):601-12. https://doi.org/10.1111/j.1552-6909.2009.01059.x PMid:19883483

39. Mancuso JM. Health literacy: a concept/dimensional analysis. Nursing \& health sciences. 2008;10(3):248-55. https://doi.org/10.1111/j.1442-2018.2008.00394.x PMid:18786068

40. Coleman C. Teaching health care professionals about health literacy: A review of the literature. Nursing outlook. 2011;59(2):70-8. https://doi.org/10.1016/j.outlook.2010.12.004 PMid:21402202

41. Haun JN, Patel NR, French DD, Campbell RR, Bradham DD, Lapcevic WA. Association between health literacy and medical care costs in an integrated healthcare system: a regional population based study. BMC health services research. 2015;15(1):249. https://doi.org/10.1186/s12913-015-0887-z PMid:26113118 PMCid:PMC4482196

42. Volandes $A E$, Paasche-Orlow MK. Health literacy, health inequality and a just healthcare system. The American Journal of Bioethics. 2007;7(11):5-10. https://doi.org/10.1080/15265160701638520 https://doi.org/10.1080/15265160701769341 PMid:18027287

43. Wilson P, Leitner C, Moussalli A. Mapping the Potential of eHealth: Empowering the Citizen through eHealth Tools 
and Services. Research Report presented at the eHealth Conference, Cork, Ireland, 5-6 May 2004: European Institute of Public Administration, Maastricht; 2004.

44. Houts PS, Doak CC, Doak LG, Loscalzo MJ. The role of pictures in improving health communication: a review of research on attention, comprehension, recall, and adherence. Patient education and counseling. 2006;61(2):173-90. https://doi.org/10.1016/j.pec.2005.05.004 PMid:16122896

45. Liu X, Rohrer W, Luo A, Fang Z, He T, Xie W. Doctorpatient communication skills training in mainland China: A systematic review of the literature. Patient education and counseling. 2015;98(1):3-14. https://doi.org/10.1016/j.pec.2014.09.012 PMid:25308954

46. Patient education booklet for freshmen Nurses. Tehran University of Medical Sciences and Health Services TDNM. 2014.
47. Wallace LS, Lennon ES. American Academy of Family Physicians patient education materials: can patients read them? Family medicine. 2004;36(8):571-4. https://doi.org/10.1249/00005768-200405001-00517

48. DW. B. The meaning and the measure of health literacy. . J Gen Intern Med 2006;21(8): 878-83. https://doi.org/10.1111/j.1525-1497.2006.00540.x PMid:16881951 PMCid:PMC1831571

49. Britigan DH, Murnan J, Rojas-Guyler L. A qualitative study examining Latino functional health literacy levels and sources of health information. Journal of Community Health. 2009;34(3):222-30. https://doi.org/10.1007/s10900-008-9145-1 PMid:19127413

50. HL. B. Health literacy: An exploratory bibliometric analysis, 1997-2007. . J Med Libr Assoc. 2009;97(2):148-50. https://doi.org/10.3163/1536-5050.97.2.016 PMid:19404510 PMCid:PMC2670206 